\title{
Eudicotiledôneas ornamentais dos campos do bioma Pampa no Rio Grande do Sul ${ }^{(1)}$
}

\author{
ANA DE ARAÚJO CARRION(2) E PAULO BRACK(3)
}

\begin{abstract}
RESUMO
O presente estudo teve como enfoque o grupo de plantas Eudicotiledôneas nativas dos campos do bioma Pampa localizado no sul do Brasil com potencial ornamental. O Pampa apresenta elevada biodiversidade, entretanto necessita de estudos quanto à riqueza de plantas vasculares e seu conhecimento biológico e ecológico. O objetivo desse trabalho foi elaborar um inventário preliminar desse grupo de vegetais, avaliando o potencial ornamental de cada espécie, indicando aquelas que poderiam ser consideradas prioritárias para uso sustentável com essa finalidade. Foram selecionadas algumas espécies campestres por meio da busca de informações em registros de herbário, obras nacionais e internacionais sobre plantas ornamentais, levantamentos florísticos, além do conhecimento prático dos autores. Foram estabelecidos alguns parâmetros e valores a eles associados, visando a reduzir a subjetividade da escolha. O levantamento resultou em uma lista de 177 espécies, distribuídas entre 36 famílias e 101 gêneros. Das 177 espécies, dez apresentaram elevado potencial ornamental. Esses dados indicam que a riqueza da flora nativa ornamental dos campos da região é elevada, ainda que pouco conhecido o seu aproveitamento. A utilização dessas plantas, desde que de forma sustentável, poderá gerar benefícios econômicos e ecológicos.
\end{abstract}

Palavras-chave: campos sulinos, flora nativa, plantas ornamentais.

\section{ABSTRACT}

Ornamental Eudicotyledons from grasslands of Pampa biome in Rio Grande do Sul

\begin{abstract}
The present study aims at investigating the group of Eudicotyledons native plants with ornamental potential of grasslands from the Pampa biome in the south of Brazil. The Pampa presents a high level of biodiversity; however, it requires studies related to the richness of vascular plants and its biological and ecological knowledge. The purpose of this work is to elaborate a preliminary inventory of this group of plants, analyzing the ornamental potential of each specie and indicating those that could be considered as being priorities for the purpose of sustainable use with this objective. Some grassland species were selected through the search for information in herbarium registers, national and international works about decorative plants, floristic surveys, besides the authors' practical knowledge. Some parameters and values were associated, aiming at reducing the subjectivity of the choice. The survey resulted in a list of 177 species distributed in 36 families and 101 genera. Among these species, ten presented high ornamental potential. These data show that the richness of the grassland native ornamental flora is high, even though its use is poorly known. The use of these plants, if in a sustainable manner, can produce economic and ecological benefits.
\end{abstract}

Keywords: grasslands from the south of Brazil, native flora, ornamental plants.

\section{INTRODUÇÃO}

O bioma Pampa ocorre no sul do Brasil, Uruguai e Argentina. No Brasil, ocorre aproximadamente na metade sul do Estado do Rio Grande do Sul (RS), alcançando uma extensão de $176.496 \mathrm{~km}^{2}$, correspondendo a cerca de $2,07 \%$ do território brasileiro e de $63 \%$ da área total do Estado (IBGE, 2004).

O Pampa apresenta como principal vegetação os campos nativos, sendo as formações florestais restritas, geralmente, a ambientes de encosta de morro, bem como a matas em galeria. O bioma revela-se um espaço rico em biodiversidade (PILLAR, 2006), possuindo relevantes diferenças regionais na estrutura de sua vegetação e na composição das espécies. Estimativas recentes, porém, ainda imprecisas, indicam que a região conjuga pelo menos 3.000 espécies de espermatófitas (BOLDRINI, 2002).

Por outro lado, tem-se assistido a uma contínua conversão dos ecossistemas campestres em outros usos, como os cultivos agrícolas homogêneos e a silvicultura em larga escala, além das frequentes queimadas nesse ambiente e do prejuízo causado pela pecuária quando mal manejada.

Apesar de grande parte de sua área ser definida como prioritária para a conservação (MMA, 2007), apenas $0,36 \%$ dos ecossistemas campestres estão protegidos em Unidades de Conservação no RS (PILAR, 2006).

Também se observa acentuada utilização de plantas brasileiras ornamentais por outros países. Contraditoriamente, no Brasil, depara-se com um ínfimo número de plantas nativas em viveiros e em floriculturas,

\footnotetext{
(1) Recebido em 11/08/2011 e aceito para publicação em 04/05/2012.

(2) Graduada em Ciências Biológicas pela Universidade Federal do Rio Grande do Sul (UFRGS), Especialista em Gestão da Qualidade para o Meio Ambiente pela Pontifícia Universidade Católica do Rio Grande do Sul e Mestranda em Desenvolvimento Rural pela UFRGS. E-mail: ana.carrion@ ufrgs.br. Rua Vitor Meireles n. 40, ap. 302, CEP 90430-160. Porto Alegre, RS, Brasil.

(3) Graduado em Ciências Biológicas pelaUFRGS, Mestre em Botânica pela UFRGS, Doutor em Ecologia e Recursos Naturais pela Universidade Federal de São Carlos, Professor do Departamento de Botânica da UFRGS. E-mail: pbrack@adufrgs.ufrgs.br. Instituto de Biociências. Av. Bento Gonçalves, n. 9500, prédio 42432. CEP 91501.970. Porto Alegre, RS, Brasil.
} 
demonstrando uma clara negligência e menosprezo com relação a esses recursos biológicos em parte pelo desconhecimento das espécies nativas (LEAL e BIONDI, 2006).

Uma planta ornamental pode ser definida como aquela "capaz de despertar resposta do senso estético particular ao ser humano" (MELLO, 1986). Apesar de o critério para a definição do que é ou não ornamental estar sujeito a certo grau de subjetividade, o pesquisador pode e deve absterse de preferências pessoais, atendo-se a alguns fatores. Entre esses fatores, estão caracteres como vistosidade e originalidade (CHAMAS e MATTHES, 2000), os quais podem ser priorizados para que se evidenciem plantas que se destacam em relação ao seu contexto e alguns atributos particulares de cada planta, como o efeito de flores ou folhagem (LORENZI e SOUZA, 2008). Entretanto, o mercado ainda está mais preocupado com uma estética convencional do que com a valorização das espécies nativas, o que pode ser decorrente do desconhecimento sobre o papel ecológico e o potencial da flora autóctone.

Poucos são os guias existentes sobre plantas ornamentais nativas do Brasil. Em nível mundial, os guias de BRICKELL (1996) e GRAF (1981) podem ser considerados obras referenciais, apresentando espécies ornamentais circunscritas às regiões tropicais e subtropicais. No que se refere a obras produzidas, abordando a flora pampiana ornamental, o primeiro trabalho encontrado é de MARCHESI (1969), em que são citadas várias espécies não somente as de campo, dos principais grupos da flora do Uruguai.

No Brasil, a primeira obra mais abrangente sobre o tema foi de HOEHNE (1930). Além desse, o trabalho de LORENZI e SOUZA (1999) pode ser considerado o mais completo guia existente para essa categoria de plantas, incluindo tanto plantas nativas quanto exóticas. Já no âmbito do RS, recentemente foi publicada uma obra inédita e importante por STUMPF et al. (2009), a qual trata de plantas ornamentais nativas do bioma Pampa, em campos, banhados, florestas e outros ecossistemas.

O objetivo do presente trabalho é realizar um levantamento preliminar de Eudicotiledôneas ${ }^{(1)}$ ornamentais nativas dos campos do bioma Pampa no sul do Brasil, avaliando o potencial de algumas dessas espécies para uso em jardins.

\section{MATERIAL E MÉTODOS}

\section{Área de estudo}

O trabalho foi desenvolvido com busca de registros de plantas na área geográfica correspondente à porção brasileira do bioma Pampa (Figuras 1 e 2), segundo o mapa de Províncias Biogeográficas (CABRERA e WILLINK, 1980) e o Mapa dos Biomas do Brasil (IBGE, 2004). As regiões geomorfológicas abrangidas pelo bioma são: Planície Costeira, Depressão Central Gaúcha (Depressão
Periférica), Planalto Meridional e Escudo Sul-RioGrandense (Planalto Sul-Rio-Grandense) (IBGE, 1986).

\section{Procedimentos de pesquisa e seleção das espécies}

Pela impossibilidade de abranger todo o grupo de Angiospermas, o estudo foi feito com Eudicotiledôneas, em um primeiro momento. Esse grupo taxonômico, reconhecido pelo sistema APG III (2009), é considerado monofilético e abrange a maior parte das Angiospermas.

Por meio de critérios de ornamentação, mais adiante descritos, para o processo de seleção de espécies campestres com valor ornamental, foi empreendida uma procura de dados sobre plantas ornamentais desse contingente. O critério adotado para a definição de espécies de campo levou em conta o ecossistema campestre e os ambientes abertos associados - campos rupestres, campos de dunas, campos úmidos, entre outros - presentes no bioma Pampa. Assim, praticamente todas as espécies são heliófitas, o que facilita a maior uniformização de habitat para seu uso prioritariamente como ornamentais de jardim. Dessa forma, não foram considerados vegetais exclusivos de florestas ou banhados. Foram utilizados registros de campo feitos pelos autores, bem como bibliografia e dados das espécies presentes no herbário ICN do Instituto de Biociências da Universidade Federal do Rio Grande do Sul (UFRGS), com ocorrências em municípios incluídos no bioma, considerando o mapa do IBGE (2004) e a Malha Municipal Digital (IBGE, 2005). Esses registros foram confrontados com citações de espécies e gêneros presentes nas quatro obras sobre plantas ornamentais de MARCHESI (1969), BRICKELL (1996), LORENZI e SOUZA (1999) e STUMPF et al. (2009).

Da mesma forma, foram consultadas exsicatas do herbário Alarich R.H. Schutz - HAS, da Fundação Zoobotânica do RS (FZB / RS), e alguns trabalhos de inventários florísticos na região. Plantas não encontradas nos herbários consultados são apresentadas como "sem registro" e têm a indicação dos respectivos municípios em que foram avistadas.

Para a seleção das espécies, foram incluídas todas as formas biológicas - ervas, subarbustos, arbustos, árvores e trepadeiras. Cada planta é apresentada por família, com seu nome popular, o registro do herbário ou número do coletor, apresentando-se também aspectos relativos a características vegetativas ou reprodutivas; neste caso, a cor dominante da flor, inflorescência ou do fruto.

Também foi utilizada a Lista da Flora Ameaçada do Rio Grande do Sul - Decreto 42.099 de 31 de dezembro de 2002 - (RIO GRANDE DO SUL, 2002), com o objetivo de avaliar a pertinência da inclusão desses vegetais na seleção, visto que sua inclusão poderia aumentar o risco de exploração extrativista. Optou-se, assim, por retirar espécies de plantas ameaçadas que estivessem em categorias acima de vulnerável (em perigo e criticamente em perigo) ou, quando mantidas, foram levadas em consideração aquelas já conhecidas e referenciadas nas obras consultadas sobre

${ }^{(1)}$ Dentro das plantas vasculares, com respeito às Angiospermas e seguindo os sistemas mais modernos de classificação, em especial o APG III (Angiosperm Phylogeny Group), o maior clado corresponde às Eudicotiledôneas, seguido das Monocotiledôneas e Angiospermas Basais. 
plantas ornamentais.

Inicialmente, foram utilizados atributos vegetativos e reprodutivos como critério de inclusão no grupo de plantas ornamentais. Para caracterização das qualidades ornamentais da planta, fez-se uso de classificação já utilizada por CHAMAS e MATTHES (2000), com ajustes, reconhecendo-se aspectos qualitativos para folhagens, flores/inflorescências e frutos coloridos.

No que se refere à ornamentalilidade da parte vegetativa, ou seja, da planta inteira e/ou da folhagem, foram consideradas diferentes formas biológicas, que não somente ervas e arbustos, incluindo-se, também, árvores que ocorrem em ambiente campestre, tradicionalmente utilizadas como ornamentais. Destacou-se, nesse aspecto, o conjunto da folhagem (folhas acinzentadas ou com disposição regular) e/ou a copa das árvores (arredondada ou de vegetação savanoide), entre outros, tratando-se de plantas já utilizadas por essas qualidades.

No que tange aos aspectos reprodutivos, foram utilizados critérios de flor e/ou frutos da seguinte maneira: plantas com presença de flores e/ou inflorescências vistosas ou frutos coloridos e vistosos, isolados ou em conjunto.

Em relação aos parâmetros considerados para os atributos e sua valoração, foram utilizados valores de escala variável, conforme o parâmetro analisado, a fim de diminuir as inferências de caráter subjetivo, da forma como consta a seguir:

A) Citações em bibliografia: $0=$ sem citação em nenhuma obra; 1 = quando citada em obra de STUMPF et al. (2009) ou uma outra espécie do mesmo gênero ornamental era citada em uma das demais obras; 2 = quando a mesma espécie era citada na obra de abrangência nacional no Brasil (LORENZI e SOUZA, 1999) ou no Uruguai (MARCHESI, 1969); 3 = para a mesma espécie citada na obra de abrangência mundial (BRICKELL, 1996).

B) Abundância/raridade ou frequência de cada uma das espécies, conforme a quantidade de coletas e também a experiência de campo dos autores: 1 = raras ou pouco abundantes e/ou pouco frequentes; 2 = abundância e/ ou frequência regular; 3 = muito abundantes e/ou muito frequentes.

C) Vistosidade, conforme o diâmetro da flor/ inflorescência ou fruto colorido, da seguinte forma: 1 = até menos de $1 \mathrm{~cm} ; 2$ a partir de $1 \mathrm{~cm}$ até menos de $3 \mathrm{~cm} ; 3$ $=$ a partir de $3 \mathrm{~cm}$.

No que se refere a atributos de valor negativo, como forma de evitar incrementos de pontuação a plantas que poderiam apresentar algum aspecto desfavorável, foram utilizados dois itens com as respectivas escalas de valor:

D) Presença de espinhos ou acúleos ou mesmo presença de substâncias tóxicas amplamente conhecidas: $0=$ sem presença; $-1=$ presença pouco destacada; $-2=$ presença muito destacada.

E) Inclusão da espécie na Lista da Flora Ameaçada do Estado do Rio Grande do Sul, conforme a categoria ou status: $0=$ sem risco de extinção ou risco em categoria inferior a vulnerável; $-1=$ vulnerável; $-2=$ em perigo ou criticamente em perigo.

$\mathrm{O}$ valor total e os valores parciais oferecem indicadores para cada espécie como forma de apreciação da importância ornamental.

\section{RESULTADOS E DISCUSSÃO}

Foram encontradas 177 espécies, distribuídas em 36 famílias (Tabela 1). As quatro famílias mais representativas são Fabaceae (38 spp.), Asteraceae (35 spp.), Verbenaceae (18 spp.) e Solanaceae (14 spp.), as quais englobam $59 \%$ do total de plantas da seleção. Outras sete famílias apresentaram entre oito e quatro espécies: Cactaceae (8 spp.), Lamiaceae (6 spp.), Malvaceae (6 spp.), Lythraceae (5 spp.), Acanthaceae (4 spp.), Apocynaceae (4 spp.) e Melastomataceae (4 spp.). Sete famílias tiveram três ou duas espécies e 18 famílias apresentaram uma espécie cada uma (Figura 3).

Essas plantas são distribuídas em 101 gêneros. Os nove gêneros mais representativos, com seis a quatro espécies, são Lupinus L. (6 spp.), Calibrachoa La Llave \& Lex. (5 spp.), Senecio L. (5 spp.), Verbena L. (5 spp.), Lantana L. (4 spp.), Lathyrus L. (4 spp.), Lippia L. (4 spp.), Senna Mill. (4 spp.) e Vernonia Schreb. (4 spp.). Trinta e um gêneros apresentam três ou duas espécies cada e 61 gêneros somente uma espécie. Com relação ao hábito das plantas, foram encontrados 123 ervas, 30 arbustos, nove árvores, nove subarbustos e seis trepadeiras.

Quanto ao aspecto considerado para a definição do potencial da espécie, se vegetativo ou reprodutivo, obteve destaque pelo fruto somente uma espécie (Solanum pseudocapsicum L.). Já pela folhagem, foi verificada a presença de sete espécies, sendo cinco arbóreas (Schinus lentiscifolius Marchand, Schinus molle L., Agarista eucalyptoides (Cham. e Schltdl.) G. Don, Sapium haematosperum Müll. Arg. e Prosopis affinis Spreng.) e duas herbáceas (Eryngium pristis Cham. \& Schltdl., Dichondra microcalyx (Hall. f.) Fabris). O restante, 169 espécies, foi selecionado pelo critério relacionado às características da flor ou da inflorescência.

Cinquênta e seis espécies, o equivalente a $32 \%$ do total, apresentaram potencial significativo, obtendo valores iguais ou superiores a seis pontos. As dez espécies que possuíram os maiores valores de potencial ornamental, entre oito e nove, foram: Calliandra brevipes Benth., Calliandra tweedii Benth., Escallonia bifida Link \& Otto, Evolvulus glomeratus Nees \& C. Mart., Glandularia cabrerae (Moldenke) Botta, Petunia integrifolia (Hook.) Schinz \& Thell. Salvia guaranitica A.St.Hil. ex Benth., Schinus molle L., Sesbania punicea (Cav.) Benth. e Verbena bonariensis L. (Figuras 4, 5 e 6). As duas famílias que tiveram mais de uma espécie nesse enquadramento foram Fabaceae e Verbenaceae. Estes resultados apontam para a importância dessas espécies e dessas famílias de plantas ornamentais. Da mesma forma, seria importante que se avaliasse, posteriormente, o grau de conhecimento e de uso sobre elas no Rio Grande do Sul.

Desse contingente de 177 espécies, 45 (25\%) foram 
citadas na bibliografia sobre plantas ornamentais, $17(10 \%)$ espécies presentes em BRICKELL (1996), correspondendo a plantas nativas de uso internacional.

Quanto àquelas eudicotiledôneas em comum no presente trabalho com aquelas eudicotiledôneas de campos e ambientes abertos do bioma Pampa citadas por STUMPF et al. (2009), verificou-se a presença de 27 espécies, o que corresponde a $43 \%$ de plantas comuns desse contingente. $\mathrm{Na}$ realidade, os últimos autores apresentaram um total de 100 espécies, porém cerca de um terço desse total se refere à citação de plantas florestais e de plantas de corte, o que não consistiu no objetivo do presente trabalho. Cabe destacar que algumas espécies comuns, detentoras de potencial ornamental e não frequentemente utilizadas para essa finalidade, como Eryngium eriophorum Cham. \& Schltdl., Eryngium sanguisorba Cham. \& Schltdl. e Schinus lentiscifolius Marchand, mereceriam estudos biológicos aplicados, principalmente no que se refere à propagação e domesticação.

Em relação às estimativas, ainda não consolidadas, quanto à riqueza da flora dos campos do bioma, considerando 3.000 espécies (BOLDRINI, 2002), podese afirmar que o número encontrado no presente trabalho corresponde a cerca de $6 \%$ da flora regional para as condições propostas. Foram verificadas dificuldades na determinação taxonômica de algumas espécies de grupos botânicos pouco estudados na região. Esse fato levanta a necessidade de pesquisas mais específicas com relação à nomenclatura e à identificação adequada de algumas espécies do Pampa, bem como de uma check list da flora regional.

Apesar dessa elevada riqueza, a oferta de plantas ornamentais nativas do RS inseridas no mercado da floricultura parece ser muito escassa. Reconhece-se, entretanto, a necessidade de estudos quanto ao nível de oferta dessas espécies nativas em relação às exóticas, em floriculturas, bem como seu uso em parques, projetos de paisagismo, jardins e, inclusive, em jardins botânicos.

No que se refere às espécies ameaçadas, constatou-se que gêneros de cactáceas (Echinopsis e Gymnocalycium) e solanáceas (Petunia spp.), amplamente citadas por BRICKELL (1996), devem receber cuidados para que se evite sua utilização sem controle, ou seja, o extrativismo em seu ambiente natural. Assim, por precaução, sua consagração de uso deveria passar por mais avaliações de riscos relacionados à possível sobre-exploração. Da mesma forma, independentemente do uso comercial, denota-se a necessidade de investimentos em ampla propagação dessas espécies para fins, prioritariamente, de conservação biológica.

Deve-se, igualmente, avaliar a pertinência de desenvolver o uso de espécies potencialmente tóxicas, a exemplo de representantes do gênero Senecio, que apresentou cinco espécies no presente trabalho. Além disso, com relação à presença de estruturas como espinhos e acúleos, típicos das cactáceas, deve-se relevar o aspecto desfavorável dessa característica. Entretanto, essas últimas podem ser aproveitadas em cercas-vivas.

Cabe salientar que a seleção das espécies poderá ser aprimorada com procedimentos semelhantes ao aplicados por STUMPF et al. (2007), submetendo-se as espécies pré-selecionadas à apreciação individual por parte de pesquisadores da área e, em seguida, à avaliação do público em geral. Igualmente relevante é apontar que uma planta, quando isolada, pode não ser considerada ornamental, mas, em associação com outras, pode passar a ter esse valor reconhecido.

A ausência de uso de espécies autóctones como ornamentais, em grande parte, está associada à escassez de pesquisa no País especialmente as relacionadas à propagação e cultivo. Quanto ao uso internacional, não se percebe que as 17 espécies nativas no Pampa citadas por BRICKELL (1996) estejam recebendo a atenção devida no que se refere à propagação e ao potencial de comercialização no Estado e no País.

Por outro lado, cabe destacar que plantas ornamentais do bioma Pampa estão sendo utilizadas em outros países, inclusive por meio de biopirataria, caso do gênero Petunia (ANNES, 2006). Há muitos anos, estrangeiros descobriram e se utilizaram principalmente de duas de suas espécies - P. axilaris (Lam.) Britton e P. integrifolia (Hook.) Schinz \& Thell., dos campos entre o sul do Brasil e o Uruguai, obtendo uma variedade híbrida de petúnia das mais utilizadas como ornamental em jardins do mundo inteiro. Cabe destacar, nesse contexto, que a Convenção Mundial da Diversidade Biológica (MCCONNELL, 1996) representa um marco por consagrar alguns princípios fundamentais como a supremacia dos Estados sobre seus recursos naturais. Porém, as políticas públicas devem estar atentas para incorporar essas informações, coibindo a pirataria e estimulando a conservação e o uso sustentável dos recursos genéticos das plantas nativas.

\section{AGRADECIMENTOS}

Agradecemos às professoras Mara R. Ritter e Sílvia T. S. Miotto, pelas sugestões e correções de grande parte do trabalho bem como aos professores e estudantes que participaram do Projeto Plantas do Futuro, entre eles Ilsi I. Boldrini, Ingrid Barros, Mariane Beretta, Martin Grings e Valdely Kinupp e aos funcionários do herbário ICN / UFRGS.

\section{REFERÊNCIAS}

APG III. An update of the Angiosperm Phylogeny Group classification for the orders and families of flowering plants: APG III. Botanical Journal of the Linnean Society, v.161, p. 105-121. 2009.

ANNES, M. H. Ibama/RS apreende flora do pampa com estrangeiros suspeitos de biopirataria. 2006. Disponível em: http://noticias.ambientebrasil.com.br/ noticia/?id=2784. Acesso em: 20 nov. 2008.

BOLDRINI, I. I. Campos sulinos: caracterização e biodiversidade. In: ARAÚJO, E. A.; SAMPAIO, E. V. S. B.; GESTINARI, L. M. T. (Org.). Biodiversidade, conservação e uso sustentável da flora do Brasil. 1. ed. Recife: Imprensa Universitária, UFRPE, 2002. v.1, p. 95-97. 
BRICKELL, C. A-Z Encyclopedia of garden plants. London: Dorling Kindersley Limited. 1996. 2v.

CABRERA, A. L. \& WILLINK, A. Biogeografia de America Latina. 2.ed. Washington: OEA, 1980.117p.

CHAMAS, C. C.; MATTHES, L. A. F. Método para levantamento de espécies nativas com potencial ornamental. Revista Brasileira de Horticultura Ornamental, Campinas, v. 6, n.1/2, p.53-63, 2000.

GRAF, A. B. Tropica: Color Cyclopedia of Exotic Plants and Trees: For Warm-Region Horticulture-In Cool Climate the Summer Garden or Sheltered Indoors. 2.ed. New Jersey: Roehrs Company, 1981. 1140 p.

HOEHNE, F. C. As Plantas Ornamentaes da Flora Brasílica. São Paulo: Secretaria de Agricultura, Indústria e Comércio, 1930. v.1, 231 p.

INSTITUTO BRASILEIRO DE GEOGRAFIA E ESTATÍSTICA (IBGE). Levantamento de Recursos Naturais, v.33 - Porto Alegre - Folha SH.22 e parte das folhas Uruguaiana SH.21 e Lagoa Mirim SI.22. Rio de Janeiro. Escala 1:1.000.000. 1986.

INSTITUTO BRASILEIRO DE GEOGRAFIA E ESTATÍSTICA (IBGE). Mapa de Biomas e de Vegetação. 2004. Disponível em: http://www.ibge.gov. br/home/presidencia/noticias/noticia visualiza.php?id noticia $=169$. Acesso em: 19 nov. 2008.

INSTITUTO BRASILEIRO DE GEOGRAFIA E ESTATÍSTICA (IBGE). Mapeamento das Unidades Territoriais - Malha Municipal Digital. 2005.

Disponível em: http://mapas.ibge.gov.br/website/divisao/. Acesso em: 01 dez. 2008.

LEAL, L.; BIONDI, D. Potencial ornamental de espécies nativas. Revista Científica Eletrônica de Engenharia Florestal, Garça, n.8, 16p., ago. 2006.

LORENZI, H.; SOUZA, H. M. Plantas ornamentais no Brasil: arbustivas, herbáceas e trepadeiras. 4.ed. Nova Odessa: Plantarum. 2008. 1088p.

MARCHESI, E. Plantas ornamentales. Montevideo: Nuestra Tierra. 1969. n.37. 60 p. (Nuestra Tierra; 37).

McCONNELL, F. The biodiversity convention: a negotiating history: a personal account of negotiating the United Nations Convention on Biological Diversity
- and after. London: Kluwer Law International, c1996.

MELLO, L. E. M. Plantas Ornamentais em Paisagismo. In: ENCONTRO NACIONAL SOBRE FLORICULTURA E PLANTAS ORNAMENTAIS, Porto Alegre, 1986. Anais... Porto Alegre: Corag, 1986. p.55-63.

MINISTÉRIO DO MEIO AMBIENTE (MMA). Mapa das Áreas Prioritárias para Conservação da Biodiversidade no RS. 2007. Projeto Biodiversidade - Áreas Prioritárias do MMA. Brasília. Disponível em: http://www.biodiversidade. rs.gov.br/arquivos/1189430879Mapa_das_Areas Prioritarias_para_Conservacao_da_Biodiversida2007.doc. Acesso em: 15 nov. 2008.

OVERBECK, G. E. et al. Brazil's neglected biome: The South Brazilian Campos. Perspectives in Plant Ecology, Evolution and Systematics, Amsterdam, n.9, p.101-116, 2007.

PILLAR, V. P. (Coord. geral) 2006. Workshop: Estudo atual e desafios para a conservação dos campos. $24 \mathrm{p}$. Disponível em: http://ecoqua.ecologia.ufrgs.br/arquivos/ Reprints\&Manuscripts/Estado_Atual_e_Desafios Conservacao_Campos_Workshop.pdf Acesso em: $04 \mathrm{dez}$. 2008.

RIO GRANDE DO SUL. 2003. Decreto 42.099, de 31 de dezembro de 2002. Declara as espécies da flora nativa ameaçadas de extinção no Estado do Rio Grande do Sul e dá outras providências. Porto Alegre. Disponível em: http://www.al.rs.gov.br/legis/M010/M0100099.ASP?Hid

Tipo $=$ TEXTO\&Hid_TodasNormas $=320 \&$ hTexto $=\& H i d$ IDNorma=320 Acesso em: 29 abr. 2009.

SUERGARAY, D.M.A.; SILVA, L. A. P. Tchê Pampa: histórias da natureza Gaúcha. In: PILLAR, V.D. et. al. (eds.) Campos Sulinos: Conservação e Uso Sustentável da Biodiversidade. Brasília: MMA, 2009. p.42-59.

STUMPF, E. R. T et al. Método para avaliação da potencialidade ornamental de flores e folhagens de corte nativas e não convencionais. Revista Brasileira de Horticultura Ornamental, Campinas, v.13, n. 2, p.143-148, 2007.

STUMPF, E. R. T. et al. Prospecção de plantas nativas do bioma pampa para uso na arte floral. BioScriba, Bahía Blanca, v.1, n. 2, p. 65-72, ago. 2008.

STUMPF, E. R. T., BARBIERI, R. L. e HEIDEN, G. Cores e formas no Bioma Pampa: plantas ornamentais nativas. Pelotas: Embrapa Clima Temperado. 2009. 276p. 
Tabela 1. Lista das Espécies de Eudicotiledôneas dos campos do bioma Pampa no Rio Grande do Sul selecionadas com uso atual ou potencial como ornamental. Categorias de cores: I - branco e/ou bege; II - amarelo e/ou laranja; III vermelho; IV - celeste e/ou azul; V - rosa e/ou lilás e/ou roxo. Legenda e valores respectivos para cada um dos parâmetros definidores do potencial ornamental:

$\mathrm{B}$ = bibliografia; $\mathrm{A}$ = abundância; $\mathrm{V}=$ vistosidade; $\mathrm{P}=$ pontas espinescentes e/ou toxidez; $\mathrm{E}=$ ameaça de extinção; $\mathrm{T}=$ total.

Table 1. List of species of eudicotyledons from Pampa biome's grasslands (Rio Grande do Sul), according to current or potential ornamental usage. Colour categories: I - white and/or beige; II - yellow and/or orange; III - red; IV - sky blue and/or blue; $V$ - pink and/or lilac and/or purple. Captions and respective values equivalent to each parameter of ornamental potencial.

$B=$ bibliography; $A=$ abundance; $V=$ noticeability; $P=$ thorn-shaped edges and/or toxicity; $E=$ danger of extinction; $T=$ total

\begin{tabular}{|c|c|c|c|c|c|c|c|c|c|c|c|c|}
\hline \multirow{2}{*}{ Família } & \multirow{2}{*}{ Nome científico } & \multirow{2}{*}{ Nome comum } & \multirow{2}{*}{ Forma Biológica } & \multirow{2}{*}{ Registro } & \multicolumn{2}{|c|}{ Atributo } & \multicolumn{6}{|c|}{ Parâmetros } \\
\hline & & & & & Veg. & Rep. & B & $\mathbf{A}$ & $\mathbf{V}$ & $\mathbf{P}$ & $\mathbf{E}$ & $\mathbf{T}$ \\
\hline Acanthaceae & $\begin{array}{c}\text { Dicliptera sericea } \\
\text { Nees }\end{array}$ & & erva & $\begin{array}{l}\text { P. Brack } 3002 \\
\text { (ICN) }\end{array}$ & & X (III) & 3 & 1 & 2 & 0 & 0 & 6 \\
\hline Acanthaceae & $\begin{array}{c}\text { Dicliptera tweediana } \\
\text { Nees }\end{array}$ & $\begin{array}{l}\text { junta-de-cobra- } \\
\text { vermelha }\end{array}$ & erva & $\begin{array}{l}\text { V.F.Kinupp } \\
2546(\text { ICN) }\end{array}$ & & X (III) & 1 & 3 & 2 & 0 & 0 & 6 \\
\hline Acanthaceae & $\begin{array}{c}\text { Hygrophila costata } \\
\text { Nees }\end{array}$ & $\begin{array}{c}\text { junta-de-cobra- } \\
\text { do-brejo }\end{array}$ & erva & $\begin{array}{l}\text { V.F.Kinupp } \\
2856(\mathrm{ICN})\end{array}$ & & $\mathrm{X}(\mathrm{I})$ & 0 & 1 & 1 & 0 & 0 & 2 \\
\hline Acanthaceae & $\begin{array}{c}\text { Ruellia morongii } \\
\text { Britton }\end{array}$ & & erva & $\begin{array}{l}\text { K. Hagelund } \\
8606(\mathrm{ICN})\end{array}$ & & $\mathrm{X}(\mathrm{I})$ & 0 & 1 & 2 & 0 & 0 & 3 \\
\hline Anacardiaceae & $\begin{array}{c}\text { Schinus lentiscifolius } \\
\text { Marchand }\end{array}$ & aroeira-cinzenta & árvore & $\begin{array}{c}\text { M. Sobral } \\
3917(\mathrm{ICN})\end{array}$ & $\mathrm{X}$ & & $1 *$ & 2 & 3 & -1 & 0 & 5 \\
\hline Anacardiaceae & Schinus molle L. & aroeira-salso & árvore & $\begin{array}{l}\text { K. Hagelund } \\
9734 \text { (ICN) }\end{array}$ & $\mathrm{X}$ & & 3 & 3 & 3 & -1 & 0 & 8 \\
\hline Apiaceae & $\begin{array}{c}\text { Eryngium } \\
\text { eriophorum Cham. \& } \\
\text { Schltdl. }\end{array}$ & gravatá-azul & erva & $\begin{array}{l}\text { M. Pinheiro } \\
373 \text { (ICN) }\end{array}$ & & $\mathrm{X}(\mathrm{IV})$ & $1 *$ & 1 & 1 & 0 & 0 & 3 \\
\hline Apiaceae & $\begin{array}{l}\text { Eryngium pristis } \\
\text { Cham. \& Schltdl. }\end{array}$ & $\begin{array}{l}\text { gravatá-língua- } \\
\text { de-tucano }\end{array}$ & erva & $\begin{array}{l}\text { R. Setubal } 36 \\
\text { (ICN) }\end{array}$ & $\mathrm{X}$ & & $1 *$ & 2 & 1 & -1 & 0 & 3 \\
\hline Apiaceae & $\begin{array}{c}\text { Eryngium } \\
\text { sanguisorba } \text { Cham. } \\
\text { \& Schltdl. }\end{array}$ & gravatá-chulé & erva & $\begin{array}{l}\text { A. Guglieri } \\
823(\mathrm{ICN})\end{array}$ & & $\mathrm{X}(\mathrm{V})$ & $1 *$ & 2 & 2 & 0 & 0 & 5 \\
\hline Apocynaceae & $\begin{array}{l}\text { Amblyopetalum } \\
\text { coeruleum Malme }\end{array}$ & & erva & $\begin{array}{l}\text { Sem registro } \\
\text { em herbário }\end{array}$ & & X (IV) & 0 & 1 & 2 & 0 & 0 & 3 \\
\hline Apocynaceae & $\begin{array}{l}\text { Macrosiphonia } \\
\text { longiflora (Desf.) } \\
\text { Müll. Arg. }\end{array}$ & velame-do-campo & erva & $\begin{array}{l}\text { M. Vignoli- } \\
\text { Silva } 46 \\
\text { (ICN) }\end{array}$ & & $\mathrm{X}(\mathrm{I})$ & $2 *$ & 1 & 3 & 0 & 0 & 6 \\
\hline Apocynaceae & $\begin{array}{c}\text { Macrosiphonia } \\
\text { petraea (A. St.-Hil.) } \\
\text { K. Schum. }\end{array}$ & velame-do-campo & erva & $\begin{array}{c}\text { M. Sobral } \\
9454(\mathrm{ICN})\end{array}$ & & $\mathrm{X}(\mathrm{I})$ & 2 & 1 & 3 & 0 & 0 & 6 \\
\hline Apocynaceae & $\begin{array}{c}\text { Mandevilla coccinea } \\
\text { (Hook. \& Arn.) } \\
\text { Woodson }\end{array}$ & jalapa-do-campo & erva & $\begin{array}{c}\text { W. } \\
\text { Fousternter } \\
(\mathrm{ICN} \mathrm{069960)}\end{array}$ & & X (III) & $2 *$ & 1 & 3 & 0 & -1 & 5 \\
\hline Asteraceae & $\begin{array}{l}\text { Aspilia montevidensis } \\
\text { (Spreng.) Kuntze }\end{array}$ & margarida-deitada & erva & $\begin{array}{l}\text { C. Mondin } \\
2507(\mathrm{ICN})\end{array}$ & & X (II) & $1 *$ & 3 & 3 & 0 & 0 & 7 \\
\hline Asteraceae & $\begin{array}{c}\text { Aspilia pascalioides } \\
\text { Griseb. }\end{array}$ & $\begin{array}{l}\text { margaridão-do- } \\
\text { campo }\end{array}$ & subarbusto & $\begin{array}{l}\text { C. Mondin } \\
2903(\mathrm{ICN})\end{array}$ & & X (II) & 0 & 1 & 3 & 0 & 0 & 4 \\
\hline Asteraceae & $\begin{array}{l}\text { Bidens laevis (L.) } \\
\text { Britton, Sterns \& } \\
\text { Poggenb. }\end{array}$ & $\begin{array}{l}\text { amor-seco-do- } \\
\text { brejo }\end{array}$ & erva & $\begin{array}{l}\text { C. Mondin } \\
2578(\mathrm{ICN})\end{array}$ & & X (II) & $1 *$ & 1 & 3 & 0 & 0 & 5 \\
\hline
\end{tabular}




\begin{tabular}{|c|c|c|c|c|c|c|c|c|c|c|c|}
\hline Asteraceae & $\begin{array}{c}\text { Calea clematidea } \\
\text { Baker }\end{array}$ & & erva & $\begin{array}{c}\text { N. } \\
\text { Matzenbacher } \\
\text { (ICN 106206) }\end{array}$ & $\mathrm{X}(\mathrm{II})$ & 0 & 1 & 2 & 0 & -1 & 2 \\
\hline Asteraceae & Calea cymosa Less. & & erva & $\begin{array}{l}\text { C. Mondin } \\
2827 \text { (ICN) }\end{array}$ & $\begin{array}{l}X(I), X \\
\text { (II) }\end{array}$ & 0 & 1 & 2 & 0 & 0 & 3 \\
\hline Asteraceae & $\begin{array}{c}\text { Centaurea tweediei } \\
\text { Hook. \& Arn. }\end{array}$ & & erva & $\begin{array}{c}\text { A. A. } \\
\text { Schneider } \\
1195(\text { ICN) }\end{array}$ & $\mathrm{X}(\mathrm{V})$ & 0 & 1 & 2 & 0 & 0 & 3 \\
\hline Asteraceae & $\begin{array}{c}\text { Criscia stricta } \\
\text { (Spreng.) Katinas }\end{array}$ & $\begin{array}{l}\text { gérbera-do- } \\
\text { campo }\end{array}$ & erva & $\begin{array}{l}\text { V.F.Kinupp } \\
\text { 3061(ICN) }\end{array}$ & X (III) & 0 & 1 & 3 & 0 & 0 & 4 \\
\hline Asteraceae & $\begin{array}{c}\text { Eupatorium } \\
\text { macrocephalum Less. }\end{array}$ & & erva & $\begin{array}{l}\text { V.F.Kinupp } \\
2540 \text { (ICN) }\end{array}$ & $\mathrm{X}(\mathrm{V})$ & $1^{*}$ & 1 & 2 & 0 & 0 & 4 \\
\hline Asteraceae & $\begin{array}{l}\text { Eupatorium } \\
\text { oblongifolium } \\
\text { (Spreng.) Baker }\end{array}$ & & erva & $\begin{array}{l}\text { S. Bordignon } \\
3185(\mathrm{ICN})\end{array}$ & $\mathrm{X}(\mathrm{I})$ & 1 & 1 & 2 & 0 & 0 & 4 \\
\hline Asteraceae & $\begin{array}{c}\text { Eupatorium } \\
\text { tanacetifolium Gillies } \\
\text { ex Hook. \& Arn. }\end{array}$ & & erva & $\begin{array}{c}\text { N. } \\
\text { Matzenbacher } \\
(\mathrm{ICN} 121452)\end{array}$ & $\mathrm{X}(\mathrm{V})$ & 2 & 2 & 2 & 0 & 0 & 6 \\
\hline Asteraceae & $\begin{array}{l}\text { Grindelia puberula } \\
\text { Hook. et Arn. }\end{array}$ & $\begin{array}{l}\text { mal-me-quer- } \\
\text { peludo }\end{array}$ & erva & $\begin{array}{l}\text { E. N. Garcia } \\
388(\mathrm{ICN})\end{array}$ & X (II) & 0 & 1 & 3 & 0 & 0 & 4 \\
\hline Asteraceae & $\begin{array}{l}\text { Heterothalamus } \\
\text { alienus (Spreng.) } \\
\text { Kuntze }\end{array}$ & $\begin{array}{l}\text { alecrim-do- } \\
\text { campo }\end{array}$ & arbusto & $\begin{array}{l}\text { A. Guglieri } \\
726(\mathrm{ICN})\end{array}$ & X (II) & $1^{*}$ & 2 & 2 & 0 & 0 & 5 \\
\hline Asteraceae & $\begin{array}{l}\text { Heterothalamus } \\
\text { rupestris Deble, } \\
\text { Oliveira et Marchiori }\end{array}$ & & arbusto & $\begin{array}{l}\text { M.L. Porto } \\
2196(\text { ICN) }\end{array}$ & X (II) & 0 & 1 & 2 & 0 & 0 & 3 \\
\hline Asteraceae & $\begin{array}{c}\text { Holocheilus } \\
\text { brasiliensis (L.) } \\
\text { Cabrera }\end{array}$ & & erva & $\begin{array}{l}\text { M. Pinheiro } \\
403 \text { (ICN) }\end{array}$ & X (I) & 0 & 1 & 2 & 0 & 0 & 3 \\
\hline Asteraceae & $\begin{array}{c}\text { Hypochaeris radicata } \\
\text { L. }\end{array}$ & $\begin{array}{l}\text { almeirão-branco; } \\
\text { radiche-silvestre }\end{array}$ & erva & $\begin{array}{l}\text { V.F.Kinupp } \\
2533 \text { (ICN) }\end{array}$ & X (II) & 0 & 2 & 2 & 0 & 0 & 4 \\
\hline Asteraceae & $\begin{array}{c}\text { Hysterionica } \\
\text { filiformis (Spreng.) } \\
\text { Cabrera }\end{array}$ & & erva & $\begin{array}{l}\text { E. N. Garcia } \\
226(\mathrm{ICN})\end{array}$ & X (II) & 0 & 1 & 2 & 0 & 0 & 3 \\
\hline Asteraceae & $\begin{array}{c}\text { Hysterionica villosa } \\
\text { (Hook.) Cabrera }\end{array}$ & & erva & $\begin{array}{l}\text { M. Sobral } \\
7691(\mathrm{ICN})\end{array}$ & X (II) & 0 & 1 & 2 & 0 & 0 & 3 \\
\hline Asteraceae & $\begin{array}{l}\text { Isostigma } \\
\text { peucedanifolium } \\
\text { (Spreng.) Less. }\end{array}$ & & erva & $\begin{array}{l}\text { C. Mondin } \\
2614(\mathrm{ICN})\end{array}$ & $\mathrm{X}(\mathrm{V})$ & 0 & 1 & 2 & 0 & 0 & 3 \\
\hline Asteraceae & $\begin{array}{l}\text { Noticastrum } \\
\text { gnaphalioides } \\
\text { (Baker) Cuatrec. }\end{array}$ & & erva & $\begin{array}{l}\text { E. Freitas } 86 \\
\text { (ICN) }\end{array}$ & $\mathrm{X}(\mathrm{I})$ & 0 & 1 & 2 & 0 & 0 & 3 \\
\hline Asteraceae & $\begin{array}{c}\text { Pamphalea } \\
\text { bupleurifolia Less. }\end{array}$ & & erva & $\begin{array}{l}\text { R. Trevisan } \\
530(\mathrm{ICN})\end{array}$ & X (I) & 0 & 1 & 1 & 0 & -1 & 1 \\
\hline Asteraceae & $\begin{array}{l}\text { Perezia multiflora } \\
\text { subsp. sonchifolia } \\
\text { (Baker) Vuilleum. }\end{array}$ & & erva & $\begin{array}{c}\text { M. Sobral } \\
3062(\mathrm{ICN})\end{array}$ & X (I) & 0 & 1 & 2 & 0 & -1 & 2 \\
\hline Asteraceae & $\begin{array}{l}\text { Schlechtendalia } \\
\text { luzulaefolia Less. }\end{array}$ & $\begin{array}{l}\text { botão-de-ouro- } \\
\text { do-campo }\end{array}$ & erva & $\begin{array}{c}\text { N. } \\
\text { Matzenbacher } \\
\text { (ICN 128058) }\end{array}$ & X (II) & 2 & 1 & 3 & 0 & -2 & 4 \\
\hline Asteraceae & $\begin{array}{l}\text { Senecio brasiliensis } \\
\text { (Spreng.) Less. }\end{array}$ & $\begin{array}{l}\text { maria-mole, flor- } \\
\text { das-almas }\end{array}$ & erva & $\begin{array}{l}\text { A. Guglieri } \\
434 \text { (ICN) }\end{array}$ & X (II) & 1 & 3 & 2 & -2 & 0 & 4 \\
\hline Asteraceae & $\begin{array}{c}\text { Senecio crassiflorus } \\
\text { (Poir.) DC. }\end{array}$ & $\begin{array}{l}\text { margarida-das- } \\
\text { dunas }\end{array}$ & erva & $\begin{array}{l}\text { V.F.Kinupp } \\
2755 \text { (ICN) }\end{array}$ & X (II) & 2 & 2 & 3 & -1 & 0 & 6 \\
\hline Asteraceae & $\begin{array}{c}\text { Senecio heterotrichus } \\
\text { DC. }\end{array}$ & margarida-melosa & erva & $\begin{array}{l}\text { R. Setubal } \\
150(\mathrm{ICN})\end{array}$ & X (II) & 1 & 2 & 2 & -1 & 0 & 4 \\
\hline Asteraceae & $\begin{array}{c}\text { Senecio icoglossus } \\
\text { DC. }\end{array}$ & $\begin{array}{l}\text { margarida-lilás- } \\
\text { do-brejo }\end{array}$ & erva & $\begin{array}{c}\text { N. } \\
\text { Matzenbacher } \\
\text { (ICN 124072) }\end{array}$ & $\mathrm{X}(\mathrm{V})$ & 2 & 2 & 3 & -1 & 0 & 6 \\
\hline Asteraceae & $\begin{array}{l}\text { Senecio selloi } \\
\text { (Spreng.) DC. }\end{array}$ & $\begin{array}{l}\text { margarida-folha- } \\
\text { gorda }\end{array}$ & erva & $\begin{array}{l}\text { E. Freitas } 019 \\
(\mathrm{ICN})\end{array}$ & X (II) & 1 & 2 & 3 & -1 & 0 & 5 \\
\hline Asteraceae & $\begin{array}{c}\text { Solidago chilensis } \\
\text { Meyen }\end{array}$ & erva-lanceta & erva & $\begin{array}{l}\text { K. Hagelund } \\
15185(\mathrm{ICN})\end{array}$ & X (II) & $1^{*}$ & 3 & 2 & 0 & 0 & 6 \\
\hline
\end{tabular}




\begin{tabular}{|c|c|c|c|c|c|c|c|c|c|c|c|c|}
\hline Asteraceae & $\begin{array}{c}\text { Trichocline humilis } \\
\text { Less. }\end{array}$ & & erva & $\begin{array}{c}\text { R. Schmidt } \\
\text { (ICN 148801) }\end{array}$ & & X (II) & 0 & 1 & 3 & 0 & 0 & 4 \\
\hline Asteraceae & $\begin{array}{c}\text { Trichocline } \\
\text { macrocephala Less. }\end{array}$ & & erva & $\begin{array}{c}\text { E.P. Schenkel } \\
185 \text { (ICN) }\end{array}$ & & $\mathrm{X}(\mathrm{III})$ & 0 & 1 & 3 & 0 & -1 & 3 \\
\hline Asteraceae & $\begin{array}{c}\text { Trixis verbasciformis } \\
\text { Less. }\end{array}$ & & erva & $\begin{array}{l}\text { M.R. Ritter } \\
1374 \text { (ICN) }\end{array}$ & & X (II) & 0 & 1 & 2 & 0 & 0 & 3 \\
\hline Asteraceae & $\begin{array}{l}\text { Vernonia brevifolia } \\
\text { Less. }\end{array}$ & & erva & $\begin{array}{c}\text { R.S. } \\
\text { Rodrigues } \\
162(\mathrm{ICN})\end{array}$ & & $\mathrm{X}(\mathrm{V})$ & 0 & 2 & 2 & 0 & 0 & 4 \\
\hline Asteraceae & Vernonia lucida Less. & & erva & $\begin{array}{l}\text { R. Setubal } 64 \\
\text { (ICN) }\end{array}$ & & $\mathrm{X}(\mathrm{V})$ & 0 & 1 & 2 & 0 & 0 & 3 \\
\hline Asteraceae & $\begin{array}{c}\text { Vernonia } \\
\text { macrocephala Less. }\end{array}$ & & erva & $\begin{array}{l}\text { M. Sobral } \\
4981 \text { (ICN) }\end{array}$ & & $\mathrm{X}(\mathrm{IV})$ & 0 & 1 & 3 & 0 & 0 & 4 \\
\hline Asteraceae & $\begin{array}{l}\text { Vernonia nudiflora } \\
\text { Less. }\end{array}$ & $\begin{array}{l}\text { alecrim-do- } \\
\text { campo }\end{array}$ & erva & $\begin{array}{l}\text { M. Pinheiro } \\
558(\mathrm{ICN})\end{array}$ & & $\mathrm{X}(\mathrm{V})$ & 0 & 3 & 2 & 0 & 0 & 5 \\
\hline Begoniaceae & $\begin{array}{c}\text { Begonia cucullata } \\
\text { Willd }\end{array}$ & begônia & erva & $\begin{array}{l}\text { M. Pinheiro } \\
419 \text { (ICN) }\end{array}$ & & $\mathrm{X}(\mathrm{I})$ & 2 & 3 & 2 & 0 & 0 & 7 \\
\hline Boraginaceae & $\begin{array}{c}\text { Moritzia ciliata } \\
\text { (Cham.) DC. ex } \\
\text { Meisn. }\end{array}$ & borragem-miúda & erva & $\begin{array}{l}\text { M. Sobral } \\
2509 \text { (ICN) }\end{array}$ & & $\mathrm{X}(\mathrm{IV})$ & 0 & 1 & 2 & 0 & -1 & 2 \\
\hline Cactaceae & $\begin{array}{c}\text { Cereus } \\
\text { hildmannianus } \\
\text { Schumann }\end{array}$ & tuna & árvore & $\begin{array}{l}\text { T. B. Breier } \\
145(\mathrm{ICN})\end{array}$ & & $\mathrm{X}(\mathrm{I})$ & $2 *$ & 3 & 3 & -2 & 0 & 6 \\
\hline Cactaceae & $\begin{array}{c}\text { Echinopsis oxygona } \\
\text { (Link.) Zucc. ex } \\
\text { Pfeiff. \& Otto }\end{array}$ & gramofone-rosa & erva & $\begin{array}{l}\text { Sem registro } \\
\text { em herbário }\end{array}$ & & $\mathrm{X}(\mathrm{V})$ & 3 & 1 & 3 & 0 & -1 & 6 \\
\hline Cactaceae & $\begin{array}{l}\text { Gymnocalycium } \\
\text { horstii Buining }\end{array}$ & & erva & $\begin{array}{l}\text { s/registro no } \\
\text { ICN }\end{array}$ & & X (II) & 1 & 1 & 3 & 0 & -2 & 3 \\
\hline Cactaceae & $\begin{array}{l}\text { Opuntia monacantha } \\
\text { (Willd.) Haw. }\end{array}$ & arumbeva & arbusto & $\begin{array}{l}\text { V.F.Kinupp } \\
2639 \text { (ICN) }\end{array}$ & & X (II) & $2 *$ & 3 & 3 & -2 & -1 & 5 \\
\hline Cactaceae & $\begin{array}{c}\text { Opuntia } \\
\text { paraguayensis } \mathrm{K} . \\
\text { Schum. }\end{array}$ & arumbeva & arbusto & $\begin{array}{l}\text { Sem registro } \\
\text { em herbário }\end{array}$ & & X (II) & 3 & 2 & 3 & -2 & 0 & 6 \\
\hline Cactaceae & $\begin{array}{c}\text { Opuntia viridirubra ( } \\
\text { F.Ritter ) P.J.Braun \& } \\
\text { Esteves }\end{array}$ & arumbeva & arbusto & $\begin{array}{l}\text { Sem registro } \\
\text { em herbário }\end{array}$ & & X (II) & 1 & 1 & 3 & -2 & 0 & 3 \\
\hline Cactaceae & $\begin{array}{l}\text { Parodia leninghausii } \\
\text { (Haage) F.H. Brandt }\end{array}$ & & erva & $\begin{array}{l}\text { Sem registro } \\
\text { em herbário }\end{array}$ & & $\mathrm{X}$ (II) & 3 & 1 & 3 & -1 & -2 & 4 \\
\hline Cactaceae & $\begin{array}{l}\text { Parodia ottonis } \\
\text { (Lehm.) N.P. Taylor }\end{array}$ & $\begin{array}{l}\text { cactos-bola- } \\
\text { amarelo }\end{array}$ & erva & $\begin{array}{l}\text { V.F.Kinupp } \\
2801(\text { ICN) }\end{array}$ & & X (II) & 2 & 2 & 3 & -1 & -1 & 5 \\
\hline Campanulaceae & $\begin{array}{c}\text { Siphocampylus } \\
\text { verticillatus G.Don }\end{array}$ & & erva & $\begin{array}{l}\text { Sem registro } \\
\text { em herbário }\end{array}$ & & $\mathrm{X}(\mathrm{III})$ & 2 & 1 & 2 & 0 & 0 & 5 \\
\hline Capparaceae & $\begin{array}{c}\text { Cleome rosea Vahl. } \\
\text { ex DC }\end{array}$ & & erva & $\begin{array}{l}\text { M.R. Ritter } \\
466 \text { (ICN) }\end{array}$ & & $\mathrm{X}(\mathrm{V})$ & 1 & 1 & 3 & 0 & 0 & 5 \\
\hline Cistaceae & $\begin{array}{l}\text { Halimium brasiliense } \\
\text { (Lam.) Grosser }\end{array}$ & $\begin{array}{l}\text { papoula-do- } \\
\text { campo }\end{array}$ & erva & $\begin{array}{l}\text { V.F.Kinupp } \\
2826(\mathrm{ICN})\end{array}$ & & X (II) & 0 & 2 & 2 & 0 & 0 & 4 \\
\hline Convolvulaceae & $\begin{array}{c}\text { Dichondra } \\
\text { microcalyx (Hall. f.) } \\
\text { Fabris }\end{array}$ & dicondra & erva & $\begin{array}{l}\text { S. C. Müller } \\
45 \text { (ICN) }\end{array}$ & $\mathrm{X}$ & & 2 & 2 & 1 & 0 & 0 & 5 \\
\hline Convolvulaceae & $\begin{array}{l}\text { Evolvulus glomeratus } \\
\text { Nees \& C. Mart. }\end{array}$ & $\begin{array}{l}\text { azulzinha, } \\
\text { evólvulo }\end{array}$ & erva & $\begin{array}{l}\text { K. Hagelund } \\
14625 \text { (ICN) }\end{array}$ & & $\mathrm{X}(\mathrm{IV})$ & 3 & 2 & 3 & 0 & 0 & 8 \\
\hline Convulvulaceae & $\begin{array}{c}\text { Convolvulus } \\
\text { bonariensis Cav. }\end{array}$ & $\begin{array}{l}\text { gramofone-do- } \\
\text { campo }\end{array}$ & erva & $\begin{array}{l}\text { K. Hagelund } \\
9777 \text { (ICN) }\end{array}$ & & $\mathrm{X}(\mathrm{I})$ & 1 & 1 & 2 & 0 & 0 & 4 \\
\hline Ericaceae & $\begin{array}{c}\text { Agarista } \\
\text { eucalyptoides (Cham. } \\
\text { \& Schltdl.) G. Don }\end{array}$ & criúva & árvore & $\begin{array}{l}\text { V.F.Kinupp } \\
3137 \text { (ICN) }\end{array}$ & $\mathrm{X}$ & & 0 & 1 & 2 & 0 & 0 & 3 \\
\hline Euphorbiaceae & $\begin{array}{c}\text { Sapium } \\
\text { haematosperum Müll. } \\
\text { Arg. }\end{array}$ & curupi, toropi & árvore & $\begin{array}{l}\text { M. Sobral } \\
6360(\mathrm{ICN})\end{array}$ & $\mathrm{X}$ & & 0 & 1 & 2 & -1 & 0 & 2 \\
\hline Fabaceae/Caes. & $\begin{array}{c}\text { Chamaecrista } \\
\text { flexuosa (L.) E. } \\
\text { Greene }\end{array}$ & peninha-amarela & subarbusto & $\begin{array}{c}\text { J. Spellmeier } \\
089 \text { (ICN) }\end{array}$ & & X (II) & 0 & 1 & 1 & 0 & 0 & 2 \\
\hline
\end{tabular}




\begin{tabular}{|c|c|c|c|c|c|c|c|c|c|c|c|}
\hline Fabaceae/Caes. & $\begin{array}{c}\text { Chamaecrista repens } \\
\text { (Vogel) Irwin \& } \\
\text { Barneby }\end{array}$ & peninha-amarela & subarbusto & $\begin{array}{l}\text { R. Camargo } \\
47 \text { (ICN) }\end{array}$ & X (II) & 0 & 1 & 1 & 0 & & 2 \\
\hline Fabaceae/Caes. & $\begin{array}{l}\text { Chamaecrista } \\
\text { rotundifolia } \\
\text { (Persoon) Greene }\end{array}$ & peninha-amarela & subarbusto & $\begin{array}{l}\text { R. Camargo } \\
53(\mathrm{ICN})\end{array}$ & X (II) & 0 & 1 & 1 & 0 & & 2 \\
\hline Fabaceae/Caes. & $\begin{array}{c}\text { Parkinsonia aculeata } \\
\text { L. }\end{array}$ & cina-cina & árvore & $\begin{array}{l}\text { S.T.S. Miotto } \\
2013 \text { (ICN) }\end{array}$ & X (II) & 2 & 2 & 3 & - & & 6 \\
\hline Fabaceae/Caes. & $\begin{array}{c}\text { Senna corymbosa } \\
\text { (Lam.) H. S. Irwin \& } \\
\text { Barneby }\end{array}$ & fedegoso & arbusto & $\begin{array}{l}\text { M.R. Ritter } \\
1368(\mathrm{ICN})\end{array}$ & X (II) & 1 & 3 & 2 & 0 & & 6 \\
\hline Fabaceae/Caes. & $\begin{array}{l}\text { Senna hirsuta (L.) } \\
\text { H.S. Irwin et Barneby }\end{array}$ & fedegoso & arbusto & $\begin{array}{l}\text { A. Flores } 469 \\
(\mathrm{ICN})\end{array}$ & X (II) & 1 & 2 & 2 & 0 & & 5 \\
\hline Fabaceae/Caes. & $\begin{array}{l}\text { Senna neglecta (Vog.) } \\
\text { H.S. Irwin et Barneby }\end{array}$ & fedegoso & arbusto & $\begin{array}{c}\text { R.S. } \\
\text { Rodrigues } \\
1066(\mathrm{ICN})\end{array}$ & X (II) & 1 & 2 & 2 & 0 & & 5 \\
\hline Fabaceae/Caes. & $\begin{array}{c}\text { Senna pendula } \\
\text { (Humb. \& Bonpl. ex } \\
\text { Willd.) H.S. Irwin \& } \\
\text { Barneby }\end{array}$ & fedegoso & arbusto & $\begin{array}{l}\text { R.Záchia } \\
5489(\mathrm{ICN})\end{array}$ & X (II) & 1 & 2 & 3 & 0 & & 6 \\
\hline Fabaceae/Fabo. & $\begin{array}{c}\text { Canavalia } \\
\text { bonariensis Lindl. }\end{array}$ & & trepadeira & $\begin{array}{l}\text { S.T.S. Miotto } \\
1975(\mathrm{ICN})\end{array}$ & $\mathrm{X}(\mathrm{V})$ & 0 & 2 & 2 & 0 & & 4 \\
\hline Fabaceae/Fabo. & $\begin{array}{c}\text { Centrosema } \\
\text { virginianum (L.) } \\
\text { Benth. }\end{array}$ & & trepadeira & $\begin{array}{c}\text { F.J.M. } \\
\text { Caporal } 170 \\
\text { (ICN) }\end{array}$ & $\mathrm{X}(\mathrm{V})$ & 0 & 2 & 2 & 0 & & 4 \\
\hline Fabaceae/Fabo. & Clitoria nana Benth. & & trepadeira & $\begin{array}{l}\text { S.T.S. Miotto } \\
2033\end{array}$ & $\mathrm{X}(\mathrm{IV})$ & 0 & 2 & 2 & 0 & & 4 \\
\hline Fabaceae/Fabo. & $\begin{array}{l}\text { Collaea stenophylla } \\
\text { (Hook. \& Arn.) } \\
\text { Benth. }\end{array}$ & & subarbusto & $\begin{array}{l}\text { K. Hagelund } \\
8155 \text { (ICN) }\end{array}$ & $\mathrm{X}(\mathrm{IV})$ & $1^{*}$ & 2 & 2 & 0 & & 5 \\
\hline Fabaceae/Fabo. & $\begin{array}{c}\text { Crotalaria tweediana } \\
\text { Benth. }\end{array}$ & & erva & $\begin{array}{l}\text { A.S. Flores } \\
155(\mathrm{ICN})\end{array}$ & X (II) & $1 *$ & 2 & 2 & 0 & & 5 \\
\hline Fabaceae/Fabo. & $\begin{array}{c}\text { Galactia marginalis } \\
\text { Benth. }\end{array}$ & & erva & $\begin{array}{l}\text { R. Lüdtke } 650 \\
\text { (ICN) }\end{array}$ & $\mathrm{X}(\mathrm{V})$ & 0 & 1 & 2 & 0 & & 3 \\
\hline Fabaceae/Fabo. & $\begin{array}{c}\text { Galactia pretiosa } \\
\text { Burkart }\end{array}$ & & erva & $\begin{array}{l}\text { R. Lüdtke } 652 \\
\text { (ICN) }\end{array}$ & $\mathrm{X}(\mathrm{V})$ & 0 & 1 & 2 & 0 & & 3 \\
\hline Fabaceae/Fabo. & $\begin{array}{l}\text { Indigofera campestris } \\
\text { Bong. Ex Benth. }\end{array}$ & & erva & $\begin{array}{l}\text { S.T.S. Miotto } \\
2143(\mathrm{ICN})\end{array}$ & X (III) & 2 & 1 & 3 & 0 & & 6 \\
\hline Fabaceae/Fabo. & $\begin{array}{c}\text { Lathyrus crassipes } \\
\text { Hook. et Arn. }\end{array}$ & & erva & $\begin{array}{c}\text { A.S. Flores } \\
(\text { ICN 114294) }\end{array}$ & $\mathrm{X}(\mathrm{V})$ & 0 & 1 & 2 & 0 & & 3 \\
\hline Fabaceae/Fabo. & $\begin{array}{c}\text { Lathyrus nervosus } \\
\text { Lam. }\end{array}$ & & trepadeira & $\begin{array}{l}\text { S.T.S. Miotto } \\
2151 \text { (ICN) }\end{array}$ & $\begin{array}{l}\text { X (V } \\
\text { e I) }\end{array}$ & 3 & 1 & 2 & 0 & & 6 \\
\hline Fabaceae/Fabo. & $\begin{array}{c}\text { Lathyrus pubescens } \\
\text { Hook. \& Arn. }\end{array}$ & $\begin{array}{l}\text { ervilha-de-cheiro; } \\
\text { ervilha-de-jardim }\end{array}$ & trepadeira & $\begin{array}{l}\text { V.F.Kinupp } \\
2684 \text { (ICN) }\end{array}$ & $\mathrm{X}(\mathrm{IV})$ & 3 & 1 & 2 & 0 & & 6 \\
\hline Fabaceae/Fabo. & $\begin{array}{c}\text { Lathyrus subulatus } \\
\text { Lam. }\end{array}$ & & erva & $\begin{array}{l}\text { K. Hagelund } \\
15272(\mathrm{ICN})\end{array}$ & $\begin{array}{c}\text { X (IV e } \\
\text { V) }\end{array}$ & 1 & 1 & 2 & 0 & & 4 \\
\hline Fabaceae/Fabo. & $\begin{array}{l}\text { Lupinus albescens } \\
\text { Hook. \& Arn. }\end{array}$ & tremoço & erva & $\begin{array}{l}\text { S. T. S. } \\
\text { Miotto } 1858 \\
\quad(\text { ICN })\end{array}$ & X (IV). & 1 & 1 & 3 & 0 & & 5 \\
\hline Fabaceae/Fabo. & $\begin{array}{c}\text { Lupinus bracteolaris } \\
\text { Desr. }\end{array}$ & tremoço & erva & $\begin{array}{l}\text { I. Conterato } \\
\text { (ICN129993) }\end{array}$ & $\mathrm{X}(\mathrm{V})$ & 1 & 2 & 3 & 0 & & 6 \\
\hline Fabaceae/Fabo. & $\begin{array}{c}\text { Lupinus gibertianus } \\
\text { C.P. Sm. }\end{array}$ & tremoço & subarbusto & $\begin{array}{l}\text { S.T.S. Miotto } \\
2254(\mathrm{ICN})\end{array}$ & $\begin{array}{c}\text { X (I e } \\
\text { V) }\end{array}$ & 1 & 1 & 3 & 0 & & 5 \\
\hline Fabaceae/Fabo. & $\begin{array}{c}\text { Lupinus lanatus } \\
\text { Benth. }\end{array}$ & tremoço & erva & $\begin{array}{l}\text { S.T.S. Miotto } \\
1881(\mathrm{ICN})\end{array}$ & $\mathrm{X}(\mathrm{IV})$ & 1 & 2 & 3 & 0 & & 6 \\
\hline Fabaceae/Fabo. & $\begin{array}{c}\text { Lupinus multiflorus } \\
\text { Desr. }\end{array}$ & & erva & $\begin{array}{l}\text { S. T. S. } \\
\text { Miotto } 1635 \\
\quad(\text { ICN })\end{array}$ & $\begin{array}{c}\text { X (II e } \\
\text { V) }\end{array}$ & 1 & 1 & 3 & 0 & & 5 \\
\hline Fabaceae/Fabo. & $\begin{array}{l}\text { Lupinus paranensis } \\
\text { C.P. Smith }\end{array}$ & & subarbusto & $\begin{array}{l}\text { M. Pinheiro } \\
235 \text { (ICN) }\end{array}$ & $\mathrm{X}(\mathrm{V})$ & 1 & 2 & 3 & 0 & & 6 \\
\hline Fabaceae/Fabo. & $\begin{array}{l}\text { Sesbania punicea } \\
\text { (Cav.) Benth. }\end{array}$ & & arbusto & $\begin{array}{l}\text { R. Lüdtke } 601 \\
\text { (ICN) }\end{array}$ & X (III) & $3 *$ & 3 & 3 & 0 & & 9 \\
\hline Fabaceae/Fabo. & $\begin{array}{l}\text { Sesbania virgata ( } \\
\text { Cav.) Pers. }\end{array}$ & & arbusto & $\begin{array}{l}\text { M.R. Ritter } \\
1346(\mathrm{ICN})\end{array}$ & X (II) & 1 & 3 & 2 & 0 & & 6 \\
\hline
\end{tabular}




\begin{tabular}{|c|c|c|c|c|c|c|c|c|c|c|c|c|}
\hline Fabaceae/Fabo. & $\begin{array}{c}\text { Trifolium } \\
\text { riograndense Burk. }\end{array}$ & & erva & $\begin{array}{c}\text { R.C. } \\
\text { Bortoluzzi } \\
822(\mathrm{ICN})\end{array}$ & & X (III) & 1 & 1 & 2 & 0 & 0 & 4 \\
\hline Fabaceae/Fabo. & $\begin{array}{l}\text { Vigna luteola (Jacq.) } \\
\text { Benth. }\end{array}$ & & erva & $\begin{array}{l}\text { J.Paz } 82 \\
(\mathrm{ICN})\end{array}$ & & $\mathrm{X}(\mathrm{II})$ & 0 & 2 & 1 & 0 & 0 & 3 \\
\hline Fabaceae/Mimo. & $\begin{array}{c}\text { Acacia caven } \\
\text { (Molina) Molina }\end{array}$ & espinilho & árvore & $\begin{array}{l}\text { K. Hagelund } \\
2533(\mathrm{ICN})\end{array}$ & & X (II) & 2 & 3 & 2 & -1 & 0 & 6 \\
\hline Fabaceae/Mimo. & $\begin{array}{c}\text { Calliandra brevipes } \\
\text { Benth. }\end{array}$ & caliandra-rosa & arbusto & $\begin{array}{c}\text { M.Sobral } \\
2368(\mathrm{ICN})\end{array}$ & & $\mathrm{X}(\mathrm{V})$ & 2 & 3 & 3 & 0 & 0 & 8 \\
\hline Fabaceae/Mimo. & $\begin{array}{l}\text { Calliandra parvifolia } \\
\text { (Hook. \& Arn.) Speg. }\end{array}$ & $\begin{array}{l}\text { caliandrinha- } \\
\text { branca }\end{array}$ & arbusto & $\begin{array}{l}\text { Sem registro } \\
\text { em Herbário }\end{array}$ & & $\begin{array}{l}\text { X (V } \\
\text { e I) }\end{array}$ & 1 & 1 & 2 & 0 & 0 & 4 \\
\hline Fabaceae/Mimo. & $\begin{array}{l}\text { Calliandra tweedii } \\
\text { Benth. }\end{array}$ & $\begin{array}{l}\text { caliandra- } \\
\text { vermelha }\end{array}$ & arbusto & $\begin{array}{l}\text { T. De Marchi } \\
147(\mathrm{ICN})\end{array}$ & & X (III) & 3 & 3 & 3 & 0 & 0 & 9 \\
\hline Fabaceae/Mimo. & $\begin{array}{c}\text { Mimosa cruenta } \\
\text { Benth. }\end{array}$ & & arbusto & $\begin{array}{l}\text { S.T.S. Miotto } \\
1428(\mathrm{ICN})\end{array}$ & & $\mathrm{X}(\mathrm{V})$ & 1 & 2 & 2 & 0 & 0 & 5 \\
\hline Fabaceae/Mimo. & $\begin{array}{c}\text { Mimosa flocculosa } \\
\text { Brurkart }\end{array}$ & & arbusto & $\begin{array}{c}\text { B. Irgang } \\
(\text { ICN 004921) }\end{array}$ & & $\mathrm{X}(\mathrm{V})$ & 2 & 2 & 2 & 0 & 0 & 6 \\
\hline Fabaceae/Mimo. & $\begin{array}{c}\text { Mimosa pilulifera } \\
\text { Benth. }\end{array}$ & & arbusto & $\begin{array}{c}\text { L. O. Castro } \\
\text { (ICN 095313) }\end{array}$ & & X (II) & 1 & 2 & 1 & 0 & 0 & 4 \\
\hline Fabaceae/Mimo. & $\begin{array}{l}\text { Prosopis affinis } \\
\text { Spreng. }\end{array}$ & algarrobo & árvore & $\begin{array}{l}\text { M. Sobral } \\
6352(\mathrm{ICN})\end{array}$ & $\mathrm{X}$ & & 0 & 1 & 3 & -1 & -1 & 2 \\
\hline Gentianaceae & $\begin{array}{c}\text { Centaurium } \\
\text { pulchellum (Sw.) } \\
\text { Druce }\end{array}$ & & erva & $\begin{array}{l}\text { V.F.Kinupp } \\
3117(\mathrm{ICN})\end{array}$ & & $\mathrm{X}(\mathrm{V})$ & 0 & 2 & 1 & 0 & 0 & 3 \\
\hline Geraniaceae & $\begin{array}{l}\text { Caesarea } \\
\text { montevidensis } \\
\text { Klotzch. }\end{array}$ & & erva & $\begin{array}{l}\text { K. Hagelund } \\
13314 \text { (ICN) }\end{array}$ & & $\mathrm{X}(\mathrm{V})$ & 0 & 1 & 2 & 0 & 0 & 3 \\
\hline Gesneriaceae & $\begin{array}{c}\text { Sinningia } \\
\text { allagophylla (Mart.) } \\
\text { Wiehler }\end{array}$ & & erva & $\begin{array}{l}\text { M. Pinheiro } \\
433 \text { (ICN) }\end{array}$ & & X (III) & 1 & 1 & 3 & 0 & 0 & 5 \\
\hline Gesneriaceae & $\begin{array}{c}\text { Sinningia } \\
\text { macrostachya } \\
\text { (Lindl.) Chautems }\end{array}$ & rainha-do-abismo & erva & $\begin{array}{l}\text { V.F.Kinupp } \\
3054 \text { (ICN) }\end{array}$ & & X (III) & $1 *$ & 1 & 2 & 0 & 0 & 4 \\
\hline Grossulariaceae & $\begin{array}{l}\text { Escallonia bifida } \\
\text { Link \& Otto }\end{array}$ & canudo-de-pito & árvore & $\begin{array}{l}\text { C.F. Jurinitz } \\
120 \text { (ICN) }\end{array}$ & & $\mathrm{X}(\mathrm{I})$ & $3 *$ & 3 & 3 & 0 & 0 & 9 \\
\hline Hydrophyllaceae & Hydrolea spinosa L. & & erva & $\begin{array}{l}\text { E. N. Garcia } \\
680(\text { ICN) }\end{array}$ & & X (IV) & 0 & 1 & 3 & 0 & 0 & 4 \\
\hline Lamiaceae & $\begin{array}{c}\text { Cunila menthoides } \\
\text { Benth. }\end{array}$ & poejo-do-campo & erva & $\begin{array}{l}\text { V.F.Kinupp } \\
2500 \text { (ICN) }\end{array}$ & & X (IV) & 0 & 1 & 2 & 0 & 0 & 3 \\
\hline Lamiaceae & $\begin{array}{l}\text { Glechon ciliata } \\
\text { Benth. }\end{array}$ & & erva & $\begin{array}{l}\text { S. Bordignon } \\
1305 \text { (ICN) }\end{array}$ & & $\mathrm{X}(\mathrm{I})$ & 0 & 1 & 2 & 0 & 0 & 3 \\
\hline Lamiaceae & $\begin{array}{l}\text { Glechon thymoides } \\
\text { Benth. }\end{array}$ & & erva & $\begin{array}{l}\text { S. Bordignon } \\
1348(\mathrm{ICN})\end{array}$ & & X (I) & 0 & 1 & 2 & 0 & 0 & 3 \\
\hline Lamiaceae & $\begin{array}{l}\text { Salvia brevipes } \\
\text { Benth. }\end{array}$ & & erva & $\begin{array}{c}\text { F.J.M. } \\
\text { Caporal (ICN } \\
\text { 142615) }\end{array}$ & & X (IV) & 0 & 1 & 2 & 0 & 0 & 3 \\
\hline Lamiaceae & $\begin{array}{l}\text { Salvia guaranitica } \\
\text { A.St.Hil. ex Benth. }\end{array}$ & sálvia-roxa & erva & $\begin{array}{l}\text { V.F.Kinupp } \\
3025 \text { (ICN) }\end{array}$ & & X (IV) & 3 & 2 & 3 & 0 & 0 & 8 \\
\hline Lamiaceae & $\begin{array}{c}\text { Salvia procurrens } \\
\text { Benth. }\end{array}$ & sálvia-azul & erva & $\begin{array}{l}\text { V.F.Kinupp } \\
2770 \text { (ICN) }\end{array}$ & & X (IV) & $1 *$ & 2 & 2 & 0 & 0 & 5 \\
\hline Lythraceae & $\begin{array}{c}\text { Cuphea } \\
\text { carthagenensis } \\
\text { (Jacq.) Macbride }\end{array}$ & sete-sangrias & erva & $\begin{array}{c}\text { A. R. } \\
\text { Gonçalves } \\
(\text { ICN 128939) }\end{array}$ & & $\mathrm{X}(\mathrm{V})$ & 1 & 3 & 1 & 0 & 0 & 5 \\
\hline Lythraceae & $\begin{array}{l}\text { Cuphea glutinosa } \\
\text { Cham. \& Schltdl. }\end{array}$ & sete-sangrias & erva & $\begin{array}{l}\text { L.F. Lima } 314 \\
\qquad(\mathrm{ICN})\end{array}$ & & $\mathrm{X}(\mathrm{V})$ & 1 & 2 & 1 & 0 & 0 & 4 \\
\hline Lythraceae & $\begin{array}{l}\text { Cuphea thymoides } \\
\text { Cham. \& Schltdl. }\end{array}$ & sete-sangrias & erva & $\begin{array}{l}\text { M. Pinheiro, } \\
508(\mathrm{ICN})\end{array}$ & & $\mathrm{X}(\mathrm{V})$ & 1 & 2 & 1 & 0 & 0 & 4 \\
\hline Lythraceae & $\begin{array}{l}\text { Heimia myrtifolia } \\
\text { Cham. \& Schltdl. }\end{array}$ & & erva & $\begin{array}{l}\text { A. Guglieri } \\
894(\mathrm{ICN})\end{array}$ & & X (II) & 1 & 3 & 2 & 0 & 0 & 6 \\
\hline Lythraceae & $\begin{array}{c}\text { Heimia salicifolia } \\
\text { Link }\end{array}$ & & erva & $\begin{array}{c}\text { F.J.M. } \\
\text { Caporal (ICN } \\
142621)\end{array}$ & & X (II) & 1 & 3 & 2 & 0 & 0 & 6 \\
\hline
\end{tabular}




\begin{tabular}{|c|c|c|c|c|c|c|c|c|c|c|c|}
\hline Malpighiaceae & $\begin{array}{l}\text { Janusia guaranitica } \\
\text { (A. St.-Hil.) A. Juss. }\end{array}$ & & trepadeira & $\begin{array}{l}\text { L.F. Lima } 207 \\
\text { (ICN) }\end{array}$ & $\mathrm{X}$ (II) & 0 & 2 & 2 & 0 & 0 & 4 \\
\hline Malvaceae & $\begin{array}{c}\text { Abutilon } \\
\text { grandifolium (Willd.) } \\
\text { SW. }\end{array}$ & $\begin{array}{l}\text { abútilo-amarelo; } \\
\text { flowering maple }\end{array}$ & arbusto & $\begin{array}{l}\text { A. M. } \\
\text { Carneiro } 615 \\
\text { (ICN) }\end{array}$ & X (II) & 1 & 2 & 2 & 0 & 0 & 5 \\
\hline Malvaceae & $\begin{array}{l}\text { Hibiscus diversifolius } \\
\text { Jacq. }\end{array}$ & $\begin{array}{l}\text { hibisco-do- } \\
\text { banhado }\end{array}$ & arbusto & $\begin{array}{l}\text { V.F.Kinupp } \\
2545 \text { (ICN) }\end{array}$ & $\mathrm{X}(\mathrm{V})$ & $1 *$ & 2 & 3 & 0 & 0 & 6 \\
\hline Malvaceae & Hibiscus striatus Cav. & $\begin{array}{l}\text { hibisco-do- } \\
\text { banhado }\end{array}$ & arbusto & $\begin{array}{l}\text { Sem registro } \\
\text { em herbário }\end{array}$ & $\mathrm{X}(\mathrm{V})$ & 1 & 2 & 3 & 0 & 0 & 6 \\
\hline Malvaceae & $\begin{array}{c}\text { Krapovickasia } \\
\text { urticifolia (St.-Hil.) } \\
\text { Fryxell }\end{array}$ & & erva & $\begin{array}{l}\text { P. Brack } 453 \\
\text { (ICN) }\end{array}$ & $\begin{array}{l}\text { X (II e } \\
\text { V) }\end{array}$ & 0 & 1 & 1 & 0 & 0 & 2 \\
\hline Malvaceae & Pavonia hastata Cav. & & erva & $\begin{array}{l}\text { M. Pinheiro } \\
534(\mathrm{ICN})\end{array}$ & $\begin{array}{l}\mathrm{X}(\mathrm{I} \text { e } \\
\mathrm{V})\end{array}$ & $1 *$ & 2 & 3 & 0 & 0 & 6 \\
\hline Malvaceae & $\begin{array}{c}\text { Waltheria douradinha } \\
\text { A. St.-Hil }\end{array}$ & & erva & $\begin{array}{c}\text { R.S. } \\
\text { Rodrigues } 44 \\
\text { (ICN) }\end{array}$ & X (II) & 0 & 2 & 2 & 0 & 0 & 4 \\
\hline Melastomataceae & $\begin{array}{c}\text { Rhynchanthera } \\
\text { dichotoma (Desr.) } \\
\text { DC. }\end{array}$ & & erva & $\begin{array}{l}\text { E. N. Garcia } \\
935(\mathrm{ICN})\end{array}$ & $\mathrm{X}(\mathrm{V})$ & 0 & 1 & 2 & 0 & 0 & 3 \\
\hline Melastomataceae & $\begin{array}{l}\text { Tibouchina asperior } \\
\text { (Cham.) Cogn. }\end{array}$ & $\begin{array}{l}\text { tibuchina-do- } \\
\text { brejo }\end{array}$ & arbusto & $\begin{array}{l}\text { L.F. Lima } 203 \\
\text { (ICN) }\end{array}$ & $\mathrm{X}(\mathrm{V})$ & $1 *$ & 2 & 3 & 0 & -1 & 5 \\
\hline Melastomataceae & $\begin{array}{l}\text { Tibouchina gracilis } \\
\text { (Bonpl.) Cogn. }\end{array}$ & & erva & $\begin{array}{l}\text { L.F. Lima } 204 \\
\text { (ICN) }\end{array}$ & $\mathrm{X}(\mathrm{V})$ & $1 *$ & 3 & 2 & 0 & 0 & 6 \\
\hline Melastomataceae & $\begin{array}{l}\text { Tibouchina urvilleana } \\
\text { (DC.) Cogn. }\end{array}$ & & arbusto & $\begin{array}{l}\text { Paulo Brack } \\
3001 \text { (ICN) }\end{array}$ & $\mathrm{X}(\mathrm{V})$ & 1 & 2 & 3 & 0 & 0 & 6 \\
\hline Myrtaceae & $\begin{array}{c}\text { Acca sellowiana } \\
\text { (Berg.) Burret }\end{array}$ & goiabeira-da-serra & arbusto & $\begin{array}{l}\text { G.H. Silveira } \\
8 \text { (ICN) }\end{array}$ & $\begin{array}{l}\mathrm{X}(\mathrm{I} \text { e } \\
\text { III) }\end{array}$ & 2 & 3 & 2 & 0 & 0 & 7 \\
\hline Onagraceae & $\begin{array}{c}\text { Ludwigia grandiflora } \\
\text { (Michx.) Greuter \& } \\
\text { Burdet }\end{array}$ & & erva & $\begin{array}{l}\text { E. N. Garcia } \\
580(\mathrm{ICN})\end{array}$ & X (II) & 1 & 1 & 2 & 0 & 0 & 4 \\
\hline Onagraceae & $\begin{array}{l}\text { Ludwigia longifolia } \\
\text { (Jacq.) Benth }\end{array}$ & & arbusto & $\begin{array}{l}\text { E. N. Garcia } \\
795(\mathrm{ICN})\end{array}$ & X (II) & 3 & 2 & 2 & 0 & 0 & 7 \\
\hline Orobanchaceae & $\begin{array}{c}\text { Agalinis communis } \\
\text { (Cham. \& Schltdl.) } \\
\text { D'Arcy }\end{array}$ & & erva & $\begin{array}{c}\text { B. Irgang } \\
(\text { ICN 106315) }\end{array}$ & $\mathrm{X}(\mathrm{V})$ & 0 & 3 & 2 & 0 & 0 & 5 \\
\hline Oxalidaceae & $\begin{array}{c}\text { Oxalis articulata } \\
\text { Savigny }\end{array}$ & & erva & $\begin{array}{c}\text { F.J.M. } \\
\text { Caporal (ICN } \\
142629)\end{array}$ & $\mathrm{X}(\mathrm{V})$ & 0 & 2 & 2 & 0 & 0 & 4 \\
\hline Oxalidaceae & $\begin{array}{l}\text { Oxalis conorrhiza } \\
\text { Jacq. }\end{array}$ & & erva & $\begin{array}{l}\text { L.F. Lima } 306 \\
\text { (ICN) }\end{array}$ & X (II) & 0 & 2 & 2 & 0 & 0 & 4 \\
\hline Oxalidaceae & $\begin{array}{c}\text { Oxalis paludosa A. } \\
\text { St-Hil. }\end{array}$ & & erva & $\begin{array}{l}\text { E. N. Garcia } \\
863(\mathrm{ICN})\end{array}$ & X (II) & 0 & 2 & 2 & 0 & 0 & 4 \\
\hline Plantaginaceae & $\begin{array}{c}\text { Angelonia } \\
\text { integerrima Spreng. }\end{array}$ & caracol-do-campo & erva & $\begin{array}{l}\text { V.F.Kinupp } \\
2496 \text { (ICN) }\end{array}$ & $\begin{array}{c}X(I \text { e } \\
\text { V) }\end{array}$ & 1 & 2 & 3 & 0 & 0 & 6 \\
\hline Plantaginaceae & $\begin{array}{c}\text { Mecardonia cf. } \\
\text { procumbens (Mill.) } \\
\text { Small }\end{array}$ & & erva & $\begin{array}{l}\text { V.F.Kinupp } \\
2418 \text { (ICN) }\end{array}$ & X (II) & 0 & 2 & 1 & 0 & 0 & 3 \\
\hline Portulacaceae & $\begin{array}{c}\text { Portulaca grandiflora } \\
\text { Hook. }\end{array}$ & onze-horas & erva & $\begin{array}{l}\text { E. Freitas } 208 \\
\text { (ICN) }\end{array}$ & X (V) & 2 & 2 & 3 & 0 & 0 & 7 \\
\hline Rubiaceae & $\begin{array}{l}\text { Richardia grandiflora } \\
\text { (Cham. \& Schltdl.) } \\
\text { Steud. }\end{array}$ & $\begin{array}{l}\text { Largeflower } \\
\text { Pusley }\end{array}$ & erva & $\begin{array}{l}\text { L.F. Lima } 223 \\
\text { (ICN) }\end{array}$ & $\mathrm{X}(\mathrm{I})$ & 0 & 2 & 2 & 0 & 0 & 4 \\
\hline Solanaceae & $\begin{array}{c}\text { Calibrachoa } \\
\text { excellens (R.E. Fr.) } \\
\text { Wijsman }\end{array}$ & & erva & $\begin{array}{l}\text { M.R. Ritter } \\
490 \text { (ICN) }\end{array}$ & $\begin{array}{l}X(V) \\
X(I)\end{array}$ & 1 & 1 & 2 & 0 & 0 & 4 \\
\hline Solanaceae & $\begin{array}{c}\text { Calibrachoa } \\
\text { heterophylla } \\
\text { (Sendtn.) Wijsman }\end{array}$ & & erva & $\begin{array}{c}\text { J.R. } \\
\text { Stehmann } 766 \\
\text { (ICN) }\end{array}$ & $\begin{array}{c}\text { X (II e } \\
\text { V) }\end{array}$ & 1 & 1 & 2 & 0 & 0 & 4 \\
\hline Solanaceae & $\begin{array}{c}\text { Calibrachoa } \\
\text { ovalifolia (Miers) } \\
\text { Stehmann \& Semir }\end{array}$ & & erva & $\begin{array}{c}\text { J.C. } \\
\text { Lindeman } \\
(\text { ICN 008305) }\end{array}$ & $\mathrm{X}(\mathrm{V})$ & $1 *$ & 1 & 2 & 0 & 0 & 4 \\
\hline
\end{tabular}




\begin{tabular}{|c|c|c|c|c|c|c|c|c|c|c|c|}
\hline Solanaceae & $\begin{array}{c}\text { Calibrachoa } \\
\text { pygmaea (R.E. Fr.) } \\
\text { Wijsman }\end{array}$ & & erva & $\begin{array}{l}\text { M. Sobral } \\
4369 \text { (ICN) }\end{array}$ & $\begin{array}{l}\mathrm{X}(\mathrm{I} \text { e } \\
\mathrm{V})\end{array}$ & 1 & 1 & 2 & 0 & 0 & 4 \\
\hline Solanaceae & $\begin{array}{l}\text { Calibrachoa } \\
\text { thymifolia (A. St.- } \\
\text { Hil.) Stehmann \& } \\
\text { Semir }\end{array}$ & & erva & $\begin{array}{l}\text { M. Sobral } \\
3278 \text { (ICN) }\end{array}$ & $\mathrm{X}(\mathrm{V})$ & 2 & 1 & 2 & 0 & 0 & 5 \\
\hline Solanaceae & $\begin{array}{c}\text { Nicotiana alata Link } \\
\text { \& Otto }\end{array}$ & fumo-de-jardim & erva & $\begin{array}{l}\text { J.R. Stehmann } \\
2066(\mathrm{ICN})\end{array}$ & $\mathrm{X}(\mathrm{I})$ & 3 & 2 & 3 & -2 & 0 & 6 \\
\hline Solanaceae & $\begin{array}{c}\text { Nicotiana longiflora } \\
\text { Cav. }\end{array}$ & fumo-de-jardim & erva & $\begin{array}{l}\text { M. Vignoli- } \\
\text { Silva } 34 \\
\text { (ICN) }\end{array}$ & $\mathrm{X}(\mathrm{I})$ & 1 & 2 & 3 & -2 & 0 & 4 \\
\hline Solanaceae & $\begin{array}{l}\text { Nierembergia cf. } \\
\text { micrantha } \text { Cabrera }\end{array}$ & & erva & $\begin{array}{l}\text { V.F.Kinupp } \\
3051 \text { (ICN) }\end{array}$ & X (I) & 0 & 2 & 2 & -1 & 0 & 3 \\
\hline Solanaceae & $\begin{array}{l}\text { Nierembergia } \\
\text { riograndensis Hunz. } \\
\text { \& A.A. Cocucci }\end{array}$ & & erva & $\begin{array}{l}\text { S. Bordignon } \\
1075(\text { ICN })\end{array}$ & X (I) & 0 & 2 & 2 & -1 & 0 & 3 \\
\hline Solanaceae & $\begin{array}{l}\text { Nierembergia } \\
\text { scoparia } \text { Sendtn. }\end{array}$ & & erva & $\begin{array}{l}\text { M. Vignoli- } \\
\text { Silva } 19 \\
\text { (ICN) }\end{array}$ & X (I) & 0 & 2 & 2 & -1 & 0 & 3 \\
\hline Solanaceae & $\begin{array}{l}\text { Petunia axillaris } \\
\text { (Lam.) Britton }\end{array}$ & petúnia-branca & erva & $\begin{array}{l}\text { V.F.Kinupp } \\
2495 \text { (ICN) }\end{array}$ & X (I) & $2^{*}$ & 2 & 3 & 0 & 0 & 7 \\
\hline Solanaceae & $\begin{array}{l}\text { Petunia bajeensis T. } \\
\text { Ando \& Hashim }\end{array}$ & petúnia-rosa & erva & $\begin{array}{l}\text { J.R. Stehmann } \\
4460(\mathrm{ICN})\end{array}$ & $\mathrm{X}(\mathrm{V})$ & 1 & 1 & 3 & 0 & 0 & 5 \\
\hline Solanaceae & $\begin{array}{c}\text { Petunia integrifolia } \\
\text { (Hook.) Schinz \& } \\
\text { Thell. }\end{array}$ & petúnia-lilás & erva & $\begin{array}{l}\text { E.Soares } 214 \\
\qquad(\mathrm{ICN})\end{array}$ & $\mathrm{X}(\mathrm{V})$ & 2 & 3 & 3 & 0 & 0 & 8 \\
\hline Solanaceae & $\begin{array}{c}\text { Solanum } \\
\text { pseudocapsicum } \mathrm{L} \text {. }\end{array}$ & $\begin{array}{l}\text { tomatinho-de- } \\
\text { jardim }\end{array}$ & erva & $\begin{array}{l}\text { R.Záchia } \\
5728 \text { (ICN) }\end{array}$ & X (III) & 3 & 3 & 2 & -1 & 0 & 7 \\
\hline Turneraceae & Turnera sidoides L. & & erva & $\begin{array}{c}\text { A. Schneider } \\
1521 \text { (ICN) }\end{array}$ & $\mathrm{X}(\mathrm{V})$ & 0 & 2 & 2 & 0 & 0 & 4 \\
\hline Verbenaceae & $\begin{array}{c}\text { Aloysia } \\
\text { chamaedryfolia } \\
\text { Cham. }\end{array}$ & & arbusto & $\begin{array}{l}\text { V.F.Kinupp } \\
2861 \text { (ICN) }\end{array}$ & $\mathrm{X}(\mathrm{I})$ & 0 & 2 & 2 & 0 & 0 & 4 \\
\hline Verbenaceae & $\begin{array}{c}\text { Aloysia gratissima } \\
\text { (Gillies \& Hook.) } \\
\text { Tronc. }\end{array}$ & erva-santa & arbusto & $\begin{array}{c}\text { T. C. de } \\
\text { Marchi } 213 \\
\quad(\mathrm{ICN})\end{array}$ & $\mathrm{X}(\mathrm{I})$ & 0 & 2 & 2 & 0 & 0 & 4 \\
\hline Verbenaceae & $\begin{array}{l}\text { Glandularia cabrerae } \\
\text { (Moldenke) Botta }\end{array}$ & & erva & $\begin{array}{c}\text { Longhi- } \\
\text { Wagner } \\
10150(\mathrm{ICN})\end{array}$ & X (III) & 3 & 2 & 3 & 0 & 0 & 8 \\
\hline Verbenaceae & $\begin{array}{c}\text { Glandularia } \\
\text { pulchella (Sweet) } \\
\text { Tronc. }\end{array}$ & & erva & $\begin{array}{l}\text { G.L.G. Soares } \\
\text { (ICN 142178) }\end{array}$ & $\mathrm{X}(\mathrm{V})$ & 2 & 2 & 3 & 0 & 0 & 7 \\
\hline Verbenaceae & $\begin{array}{l}\text { Glandularia selloi } \\
\text { (Spreng.) Tronc. }\end{array}$ & & erva & $\begin{array}{c}\text { A. M. } \\
\text { Carneiro, } 662 \\
\text { (ICN) }\end{array}$ & $\mathrm{X}(\mathrm{V})$ & $1^{*}$ & 2 & 3 & 0 & 0 & 6 \\
\hline Verbenaceae & Lantana camara $\mathrm{L}$. & $\begin{array}{l}\text { camaradinha, } \\
\text { lantana }\end{array}$ & arbusto & $\begin{array}{l}\text { L.F. Lima, } \\
183 \text { (ICN) }\end{array}$ & X (II) & 2 & 3 & 3 & -1 & 0 & 7 \\
\hline Verbenaceae & Lantana fucata Lindl. & & arbusto & $\begin{array}{l}\text { A. Guglieri } \\
444 \text { (ICN) }\end{array}$ & $\mathrm{X}(\mathrm{V})$ & 2 & 2 & 3 & 0 & 0 & 7 \\
\hline Verbenaceae & $\begin{array}{c}\text { Lantana } \\
\text { megapotamica } \\
\text { (Spreng.) Tronc. }\end{array}$ & lantana-lilás & arbusto & $\begin{array}{l}\text { M. Pinheiro } \\
523 \text { (ICN) }\end{array}$ & $\mathrm{X}(\mathrm{V})$ & 1 & 2 & 3 & 0 & 0 & 6 \\
\hline Verbenaceae & $\begin{array}{c}\text { Lantana } \\
\text { montevidensis } \\
\text { (Spreng.) Briq. }\end{array}$ & lantaninha-rosa & arbusto & $\begin{array}{l}\text { R.Záchia } \\
5708 \text { (ICN) }\end{array}$ & $\mathrm{X}(\mathrm{V})$ & 2 & 2 & 3 & 0 & 0 & 7 \\
\hline Verbenaceae & $\begin{array}{c}\text { Lippia arechavaletae } \\
\text { Moldenke }\end{array}$ & & erva & $\begin{array}{l}\text { M. Sobral } \\
2515 \text { (ICN) }\end{array}$ & X (II) & 1 & 1 & 2 & 0 & 0 & 4 \\
\hline Verbenaceae & $\begin{array}{l}\text { Lippia asperrima } \\
\text { Cham. }\end{array}$ & & subarbusto & $\begin{array}{l}\text { D. Lima (ICN } \\
\text { 20990) }\end{array}$ & X (II) & 1 & 1 & 3 & 0 & 0 & 5 \\
\hline Verbenaceae & $\begin{array}{l}\text { Lippia ramboi } \\
\text { Moldenke }\end{array}$ & & subarbusto & $\begin{array}{c}\text { J. A. } \\
\text { Jarenkow } \\
1500(\mathrm{ICN})\end{array}$ & $\mathrm{X}(\mathrm{V})$ & 1 & 1 & 3 & 0 & 0 & 5 \\
\hline
\end{tabular}




\begin{tabular}{|c|c|c|c|c|c|c|c|c|c|c|c|}
\hline Verbenaceae & $\begin{array}{c}\text { Lippia turnerifolia } \\
\text { Cham. }\end{array}$ & & erva & $\begin{array}{l}\text { C. Mondin } \\
852 \text { (ICN) }\end{array}$ & X (II) & 1 & 1 & 2 & 0 & 0 & 4 \\
\hline Verbenaceae & $\begin{array}{c}\text { Verbena bonariensis } \\
\text { L. }\end{array}$ & & erva & $\begin{array}{l}\text { K. Hagelund } \\
07421(\text { ICN) }\end{array}$ & $\mathrm{X}(\mathrm{V})$ & 3 & 3 & 3 & 0 & 0 & 9 \\
\hline Verbenaceae & $\begin{array}{l}\text { Verbena } \\
\text { montevidensis } \\
\text { Spreng. }\end{array}$ & & erva & $\begin{array}{l}\text { L.F. Lima } 291 \\
\text { (ICN) }\end{array}$ & $\mathrm{X}(\mathrm{V})$ & 1 & 2 & 2 & 0 & 0 & 5 \\
\hline Verbenaceae & $\begin{array}{l}\text { Verbena rigida } \\
\text { Spreng. }\end{array}$ & $\begin{array}{l}\text { quatro-cantos, } \\
\text { Veined Verbena }\end{array}$ & erva & $\begin{array}{c}\text { M. Sobral } \\
7696(\mathrm{ICN})\end{array}$ & $\mathrm{X}(\mathrm{V})$ & 2 & 2 & 2 & 0 & 0 & 6 \\
\hline Verbenaceae & $\begin{array}{c}\text { Verbena strigosa } \\
\text { Cham. }\end{array}$ & & erva & $\begin{array}{c}\text { M Sobral } \\
8683(\mathrm{ICN})\end{array}$ & $\mathrm{X}(\mathrm{IV})$ & 1 & 1 & 2 & 0 & 0 & 4 \\
\hline Verbenaceae & $\begin{array}{c}\text { Verbena thymoides } \\
\text { Cham. }\end{array}$ & & erva & $\begin{array}{l}\text { K. Hagelund } \\
13057 \text { (ICN) }\end{array}$ & $\mathrm{X}(\mathrm{V})$ & 1 & 1 & 2 & 0 & 0 & 4 \\
\hline Violacaceae & $\begin{array}{l}\text { Hybanthus bicolor } \\
\text { (A. St.-Hil.) Baill. }\end{array}$ & & erva & $\begin{array}{l}\text { V.F.Kinupp } \\
2795 \text { (ICN) }\end{array}$ & $\mathrm{X}(\mathrm{V})$ & $1 *$ & 2 & 2 & 0 & 0 & 5 \\
\hline
\end{tabular}

* Espécie citada também por Stumpf et al. (2009)

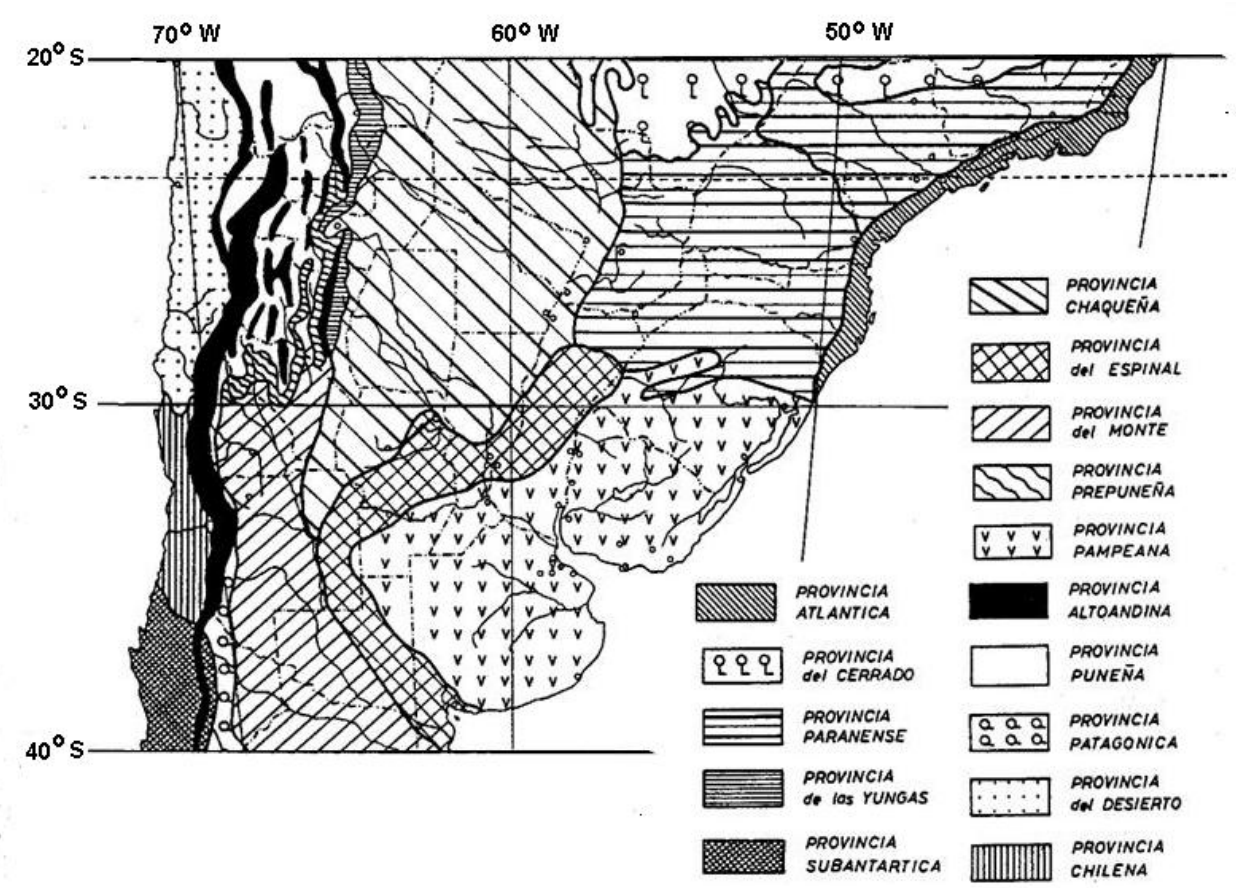

Figura 1. Mapa de províncias fitogeográficas - Fonte: Cabrera e Willink (1980).

Figure 1. Map of phytogeographical provinces - Source: Cabrera e Willink (1980).

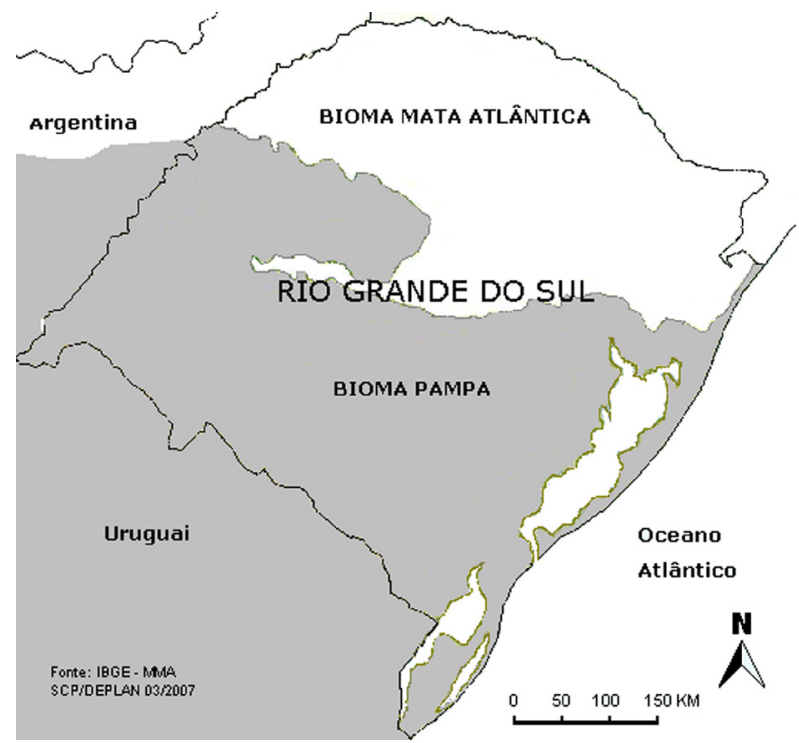

Figura 2. Mapa de biomas no Rio Grande do Sul.

Figure 2. Map of biomes in Rio Grande do Sul. 


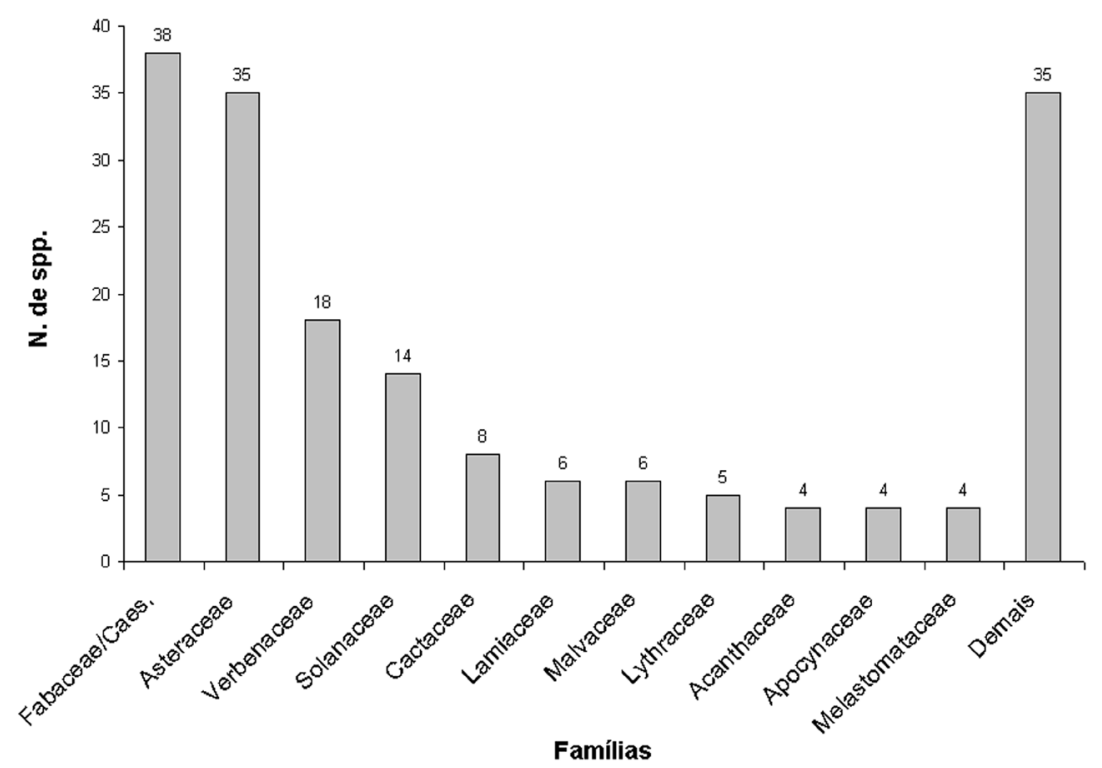

Figura 3. Distribuição de espécies de eudicotiledôneas por família. Figure 3. Distribution of species according to Family.
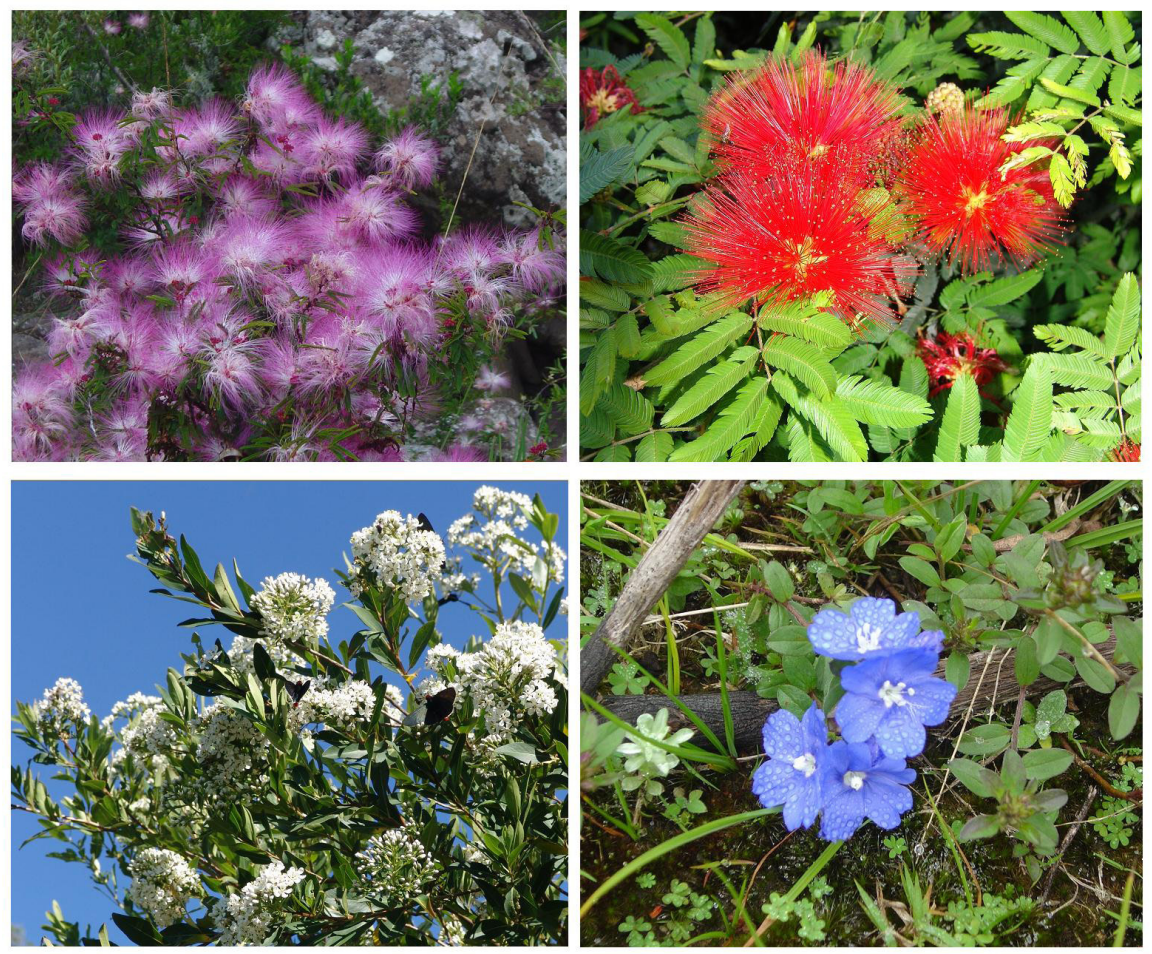

Figura 4. Espécies de eudicotiledôneas ornamentais selecionadas. Da direita para a esquerda: Calliandra brevipes Benth.; Calliandra tweedii Benth.; Escallonia bifida Link e Otto; Evolvulus glomeratus Nees e C. Mart.

Figure 4. Selected species of ornamental Eudicotyledons. From right to left: $\underline{\text { Calliandra brevipes Benth.; Calliandra }}$ tweedii Benth.; Escallonia bifida Link \& Otto; Evolvulus glomeratus Nees \& C. Mart. 

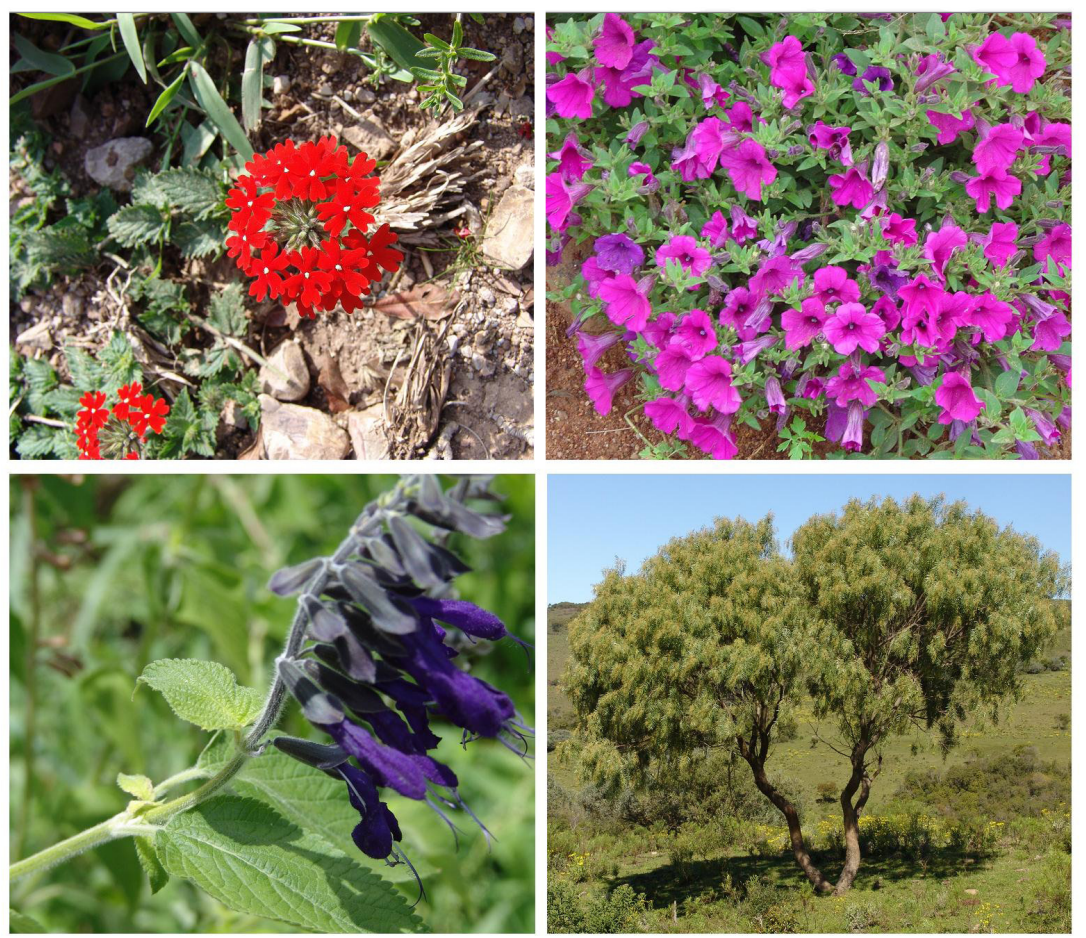

Figura 5. Espécies de eudicotiledôneas ornamentais selecionadas. Da direita para a esquerda: Glandularia cabrerae

(Moldenke) Botta; Petunia integrifolia (Hook.); Salvia guaranitica A.St.Hil. ex Benth.; Schinus molle L.

Figure 5. Selected species of ornamental Eudicotyledons. From right to left: Glandularia cabrerae (Moldenke) Botta; Petunia integrifolia (Hook.); Salvia guaranitica A.St.Hil. ex Benth.; Schinus molle L.
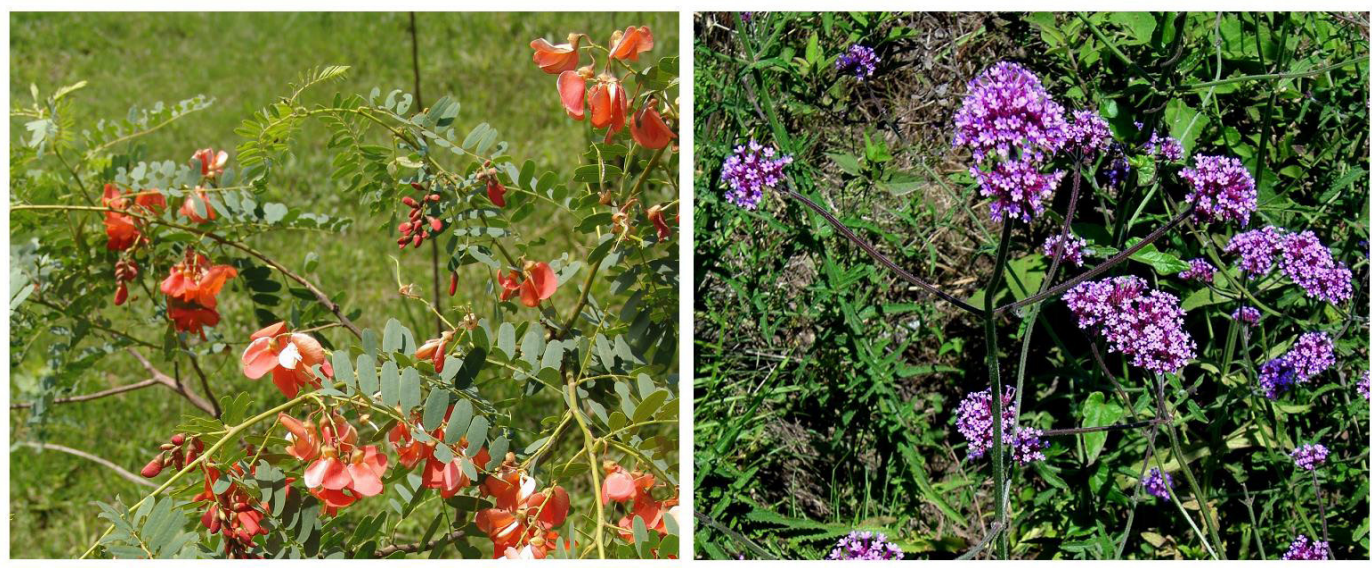

Figura 6. Espécies de eudicotiledônias ornamentais selecionadas. Da direita para a esquerda: Sesbania punicea (Cav.) Benth.; Verbena bonariensis L.

Figure 6. Selected species of ornamental Eudicotyledons. From right to left: Sesbania punicea (Cav.) Benth.; Verbena bonariensis $L$. 